\title{
Exploring the utility and effectiveness of the IEC (International Electrotechnical Commission) wave energy resource assessment and characterisation standard: A case study
}

\author{
V. Ramos ${ }^{\text {b, * }}$, John V. Ringwood ${ }^{a}$ \\ a Centre for Ocean Energy Research (COER), Maynooth University, Co. Kildare, Ireland \\ ${ }^{\mathrm{b}}$ Hydraulic Engineering, University of Santiago de Compostela, EPS, Lugo, Spain
}

\section{A R T I C L E I N F O}

\section{Article history:}

Received 11 December 2015

Received in revised form

11 April 2016

Accepted 12 April 2016

\section{Keywords:}

Wave energy

IEC-62600-101

Irish West Coast

SWAN

Intra-annual resource variability

\begin{abstract}
A B S T R A C T
For wave energy to become a commercially viable source of energy, a complete understanding of the wave resource characterisation is needed. In this context, the IEC (International Electrotechnical Commission) has developed a technical specification for the assessment of the wave resource, IEC-TS 62600101: Marine energy-Wave, tidal and other water current converters-Part 101: Wave energy resource assessment and characterisation (IEC-62600-101), which presents a series of recommendations for standardising wave resource characterisation. The IEC-62600-101 classifies resource assessment studies into three different classes: reconnaissance, feasibility and design. The model setup requirements (mesh resolution, boundary conditions) and the effort (validation process, computational times) vary considerably from one class to the other. On these grounds, the objective of this work is to explore this methodology using the Irish West Coast as a case study. Overall, it was found that the methodology proposed performs well, offering a detailed characterisation of the resource; however, with the aim of making the technical specification more manageable, some aspects related to the seasonality of the wave resource and the validation and model setup procedures may be revisited for future editions.
\end{abstract}

() 2016 Elsevier Ltd. All rights reserved.

\section{Introduction}

Over the last two decades, concerns regarding the sustainability and the environmental problems associated with fossil fuel-based energy systems have prompted various policies [1-3], which aim to encourage the use of renewable energy sources. Within the wide variety of renewables, marine energy has aroused great interest in both the academic and industrial communities, due to its large energy potential [4-11]. Among them, wave energy appears as a promising, virtually untapped, alternative [4,12], with a lot of sites around the world capable of being exploited [13-22].

On the other hand, there are some issues that must be addressed in detail, so that wave energy can become a fully-fledged renewable energy source [23-25]. Among them, the level of uncertainty in the assessment of the wave energy resource stands out [26-28]. So far, wave resource characterisation was mainly carried out based on a relatively small number of sea states, which were propagated

\footnotetext{
* Corresponding author.

E-mail address: josevictor.ramos@eeng.nuim.ie (V. Ramos).
}

towards the shore by means of spectral wave models [17,29,30], with the aim of determining the average wave power over a coastal region. However, for a better understanding of the practical resource, the assessment should cover a large portion of the available energy (at least 90\%) [31] and also take into consideration the seasonal variability of the resource [32-35].

To this end, the IEC (International Electrotechnical Commission) has recently put forward a series of recommendations to develop a standard methodology with the aim of ensuring consistency and accuracy in wave resource characterisation: IEC-TS 62600-101: Marine energy Wave, tidal and other water current converters-Part 101: Wave energy resource assessment and characterisation (from now on referred as IEC-62600-101) [36]. The IEC-62600-101 classifies the resource assessment studies into three different categories: reconnaissance, feasibility and design, with the associated notation of classes 1, 2 and 3, respectively. Class 1 is intended to obtain a first approximation of the wave energy resource over a relatively large area of seascape and would be the first resource assessment conducted in a region. Class 2 assessments are focused on smaller areas being suitable for refinement of the results obtained from the Class 1 assessments. Finally, Class 3 assessments 
are used to obtain a detailed characterisation in a relatively small area of seascape for the final project design stage, producing results with a low degree of uncertainty. In addition, IEC-62600-101 also offers a wide set of recommendations regarding the procedure to follow in the fields of data collection, numerical modelling, data analysis and the reporting of the results.

From the modelling standpoint, the impact on the wave model setup process varies considerably depending on the class considered, especially in terms of the boundary condition data and mesh resolution requirements, with the result that the level of effort required for the modelling process varies significantly from one class to another. For these reasons, the objective of the study reported in this paper is two-fold: (i) to compare the three different classes of the IEC-62600-101 in terms of uncertainty in the resource assessment and the effort required for the model setup (mesh resolution, wave data and computational times) and (ii) to provide feedback into the IEC-62600-101 with the aim of offering both practical recommendations to the users and future edits to be considered during potential IEC-62600-101 revision.

For this purpose, the Irish West Coast was used as case study. With this location, facing the North Atlantic, the Irish West Coast presents one of the most energetic wave climates in the world [37] and, therefore, it appears as one of the most promising locations for harvesting the wave energy resource. Although detailed studies $[37,38]$ have dealt with the wave climate and wave energy resource of the region, none has been carried out following the procedures of IEC-62600-101. For all the above mentioned reasons, this region appears as an excellent location to illustrate the methodology proposed by the IEC-62600-101.

The remainder of the paper is structured as follows: Section 2 presents the main characteristics of the IEC-62600-101. Sections 3,4 and 5, present the main aspects of the case study used in this investigation. Section 6 shows the results obtained during validation and wave resource characterisation. Section 7, presents a discussion regarding the most relevant aspects of the IEC-62600-101. Finally, conclusions are drawn in Section 8.

\section{IEC 62600-101 TS: marine energy - wave, tidal and other water current converters-part 101: wave energy resource assessment and characterisation}

IEC-62600-101, mainly intended for project developers, device developers, policy-makers and investors, aims to set a series of standards related to the measurement, modelling, analysis and reporting of the wave energy resource, and the linkages between these activities. It is important to point out that this is the first version of the standard and, therefore, it will be subject to change based on the feedback received from the different agents involved in a wave energy project. In this section, the main characteristics of the IEC-62600-101 regarding the modelling aspects will be presented. For further details in other aspects, such as data collection and data analysis, the readers are referred to the IEC-62600-101 document [36].

\subsection{IEC 62600-101: wave model setup}

As mentioned in the previous section, the technical specification divides the resource assessment studies into three different categories: reconnaissance, feasibility and design, with the notation of Class 1, 2 and 3, respectively. The main characteristics of each class are summarised in Table 1.

Regardless of the class considered, the numerical model used to estimate the resource should produce a minimum of ten years of sea state data, which shall be generated with a minimum frequency of one data point every three hours. However, for each class, the
Table 1

Classes of resource assessment IEC-62600-101.

\begin{tabular}{lllll}
\hline Class & Description & Uncertainty & & $\frac{\text { Long-shore }}{}$ \\
\cline { 5 - 5 } & Wave resource & & Extent $(\mathrm{km})$ \\
\hline Class 1 & Reconnaissance & High & $>300$ \\
Class 2 & Feasibility & Medium & $20-500$ \\
Class 3 & Design & Low & $<25$ \\
\hline
\end{tabular}

model setup requirements vary considerably, especially regarding the physical processes that must be considered (i.e: triad and quadruplet interactions, wave breaking, whitecapping, etc ...) and also the spatial and temporal resolutions.

Regarding the wave boundary conditions, the IEC-62600-101 classifies them into three different types: (i) parametric boundaries, which are based on a predefined spectral shape (e.g. JONSWAP, Pierson-Moscowitz, Bretschneider) defined by characteristic parameters such as significant wave height, $H_{m 0}$, peak period, $T_{p}$ and mean wave direction $\theta_{m}$, (ii) hybrid boundary conditions, characterised by wave spectrum with parametric directional parameters and (iii) spectral boundaries, defined by a directional wave spectrum. For class 3 assessments, spectral boundaries are mandatory and also recommended for the rest of the classes. For classes 2 and 1, hybrid and parametric boundary conditions are also accepted, respectively. Finally, these boundary conditions should be defined using either: (i) physically recorded meteocean data, (ii) historical data obtained from a more extensive numerical model or (iii) a combination of the first two options. In all cases, the data should cover a period of at least ten years, with a data return rate greater than $70 \%$ for the case of the recorded meteocean data. Furthermore, a combination of meteocean and modelled data can be used to fill in the missing information from the recorded data set.

Table 2

IEC-62600-101 model setup recommendations.

\begin{tabular}{|c|c|c|c|}
\hline Component & Class 1 & Class 2 & Class 3 \\
\hline \multicolumn{4}{|l|}{ Physical processes } \\
\hline $\begin{array}{l}\text { Wind-wave growth } \\
\text { Whitecapping } \\
\text { Quadruplet interactions } \\
\text { Wave breaking } \\
\text { Bottom friction } \\
\text { Triad interactions } \\
\text { Diffraction } \\
\text { Refraction } \\
\text { Wave reflections } \\
\text { Wave-current interactions }\end{array}$ & $\begin{array}{l}0 \\
\bullet \\
0 \\
0 \\
0 \\
0 \\
0 \\
0 \\
0 \\
0 \\
0\end{array}$ & $\begin{array}{l}0 \\
0 \\
0 \\
0 \\
0 \\
0 \\
0 \\
0 \\
0 \\
0\end{array}$ & $\begin{array}{l}0 \\
0 \\
0 \\
0 \\
0 \\
0 \\
0 \\
0 \\
0 \\
0\end{array}$ \\
\hline \multicolumn{4}{|l|}{ Numerics } \\
\hline $\begin{array}{l}\text { Parametric wave model } \\
\text { 2nd generation Spectral wave model } \\
\text { 3rd generation Spectral wave model } \\
\text { Mild-slope wave model } \\
\text { Spherical coordinates } \\
\text { Non-stationary solution } \\
\text { Min. spatial resolution } \\
\text { Min. temporal resolution } \\
\text { Min. num. wave frequencies } \\
\text { Min. num. azimuthal direction }\end{array}$ & $\begin{array}{c}\bigcirc \\
\bigcirc \\
* \\
\bigcirc \\
\bullet \\
\bigcirc \\
5 \mathrm{~km} \\
3 \mathrm{~h} \\
25 \\
24\end{array}$ & $\begin{array}{c}\star \\
\bigcirc \\
* \\
\bigcirc \\
\bigcirc \\
\bigcirc \\
500 \mathrm{~m} \\
3 \mathrm{~h} \\
25 \\
24\end{array}$ & $\begin{array}{c}\star \\
\star \\
* \\
0 \\
0 \\
\bigcirc \\
50 \mathrm{~m} \\
1 \mathrm{~h} \\
25 \\
24\end{array}$ \\
\hline \multicolumn{4}{|l|}{ Boundary Conditions } \\
\hline $\begin{array}{l}\text { Parametric boundary } \\
\text { Hybrid boundary } \\
\text { Spectral boundary }\end{array}$ & $\begin{array}{l}0 \\
0 \\
*\end{array}$ & $\begin{array}{l}\star \\
\bigcirc \\
*\end{array}$ & $\begin{array}{l}\star \\
\star \\
*\end{array}$ \\
\hline
\end{tabular}

- Mandatory, ${ }^{*}$ Recommended, $\bigcirc$ Acceptable, $\star$ Not permitted. 
The main characteristics for the model setup process of each class are summarised in Table 2 .

\subsection{IEC 62600-101: wave model validation}

With the aim of evaluating the model's ability to accurately predict the wave resource over a coastal region, IEC-62600-101 has developed a validation procedure. Overall, when possible, the model output should be validated using data from one or more locations close to where the WECs (wave energy converters) are to be placed. If this is not possible, the validation should be carried out against similar wave conditions to those where the WECs might be deployed. The validation data set should cover a period of one year, with a monthly return rate of recorded data exceeding $70 \%$. Then, this data set must be used to construct an omni-directional $H_{m 0}-T_{e}$ scatter table showing the relative frequency of occurrence of different sea states. Finally, the validation coverage will be defined as the sum of the relative frequency of occurrence of the represented scatter table cells. A cell in the scatter table will be considered to be representative as long as it contains a minimum number of validation data points. All these requirements are detailed in Table 3.

The model error is evaluated by considering the data in each scatter table cell, and overall. For each represented cell, the normalized error, $e_{p}$, between measured and modelled values of a parameter, $p$, must be calculated as:

$e_{p}=\left[\begin{array}{c}\left|\left(p_{M 1}-p_{D 1}\right)\right| / p_{D 1} \\ \vdots \\ \left|\left(p_{M n}-p_{D n}\right)\right| / p_{D n}\end{array}\right]$

where, $p_{M k}$, and, $p_{D k}$, are values at coincident time-steps $t_{k}$ for $k=1$ $\ldots n$ of the modelled and measured parameter, respectively. For each cell, the normalised error must be separated into a systematic error, $\mu_{i j}\left(e_{p}\right)$, and a random error, $\sigma_{i j}\left(e_{p}\right)$. The systematic error, or bias, is defined as the mean of errors in cell, $(i, j)$, (Eq. (2)), whereas the random error is represented by the standard deviation of the errors in cell, $(i, j)$, (Eq. (3)):

$\mu_{i j}=\frac{1}{N} \sum_{k=1}^{N} e_{p_{i j}}$

Table 3

IEC-62600-101 validation recommendations.

\begin{tabular}{llll}
\hline & Class 1 & Class 2 & Class 3 \\
\hline Data coverage & & & \\
\hline Min. Num. of cell data points & 3 & 5 & 5 \\
Min. coverage by validation data & $90 \%$ & $90 \%$ & $95 \%$ \\
\hline Max. acceptable $b\left(e_{p}\right)$ & & & \\
\hline Sig. wave height, $H_{m 0}$ & $10 \%$ & $5 \%$ & $2 \%$ \\
Energy period, $T_{e}$ & $10 \%$ & $5 \%$ & $2 \%$ \\
Omni-directional wave power, $J$ & $25 \%$ & $12 \%$ & $5 \%$ \\
Dir. of max dir. resolved power, $\theta_{\text {Jmax }}$ & - & $10^{\circ}$ & $5^{\circ}$ \\
Spectral width, $\varepsilon_{0}$ & - & $12 \%$ & $5 \%$ \\
Directionality coefficient, $d$ & - & $12 \%$ & $5 \%$ \\
\hline Max. acceptable $\sigma\left(e_{p}\right)$ & & & \\
\hline Sig. wave height, $H_{m 0}$ & $15 \%$ & $10 \%$ & $7 \%$ \\
Energy period, $T_{e}$ & $15 \%$ & $10 \%$ & $7 \%$ \\
Omni-directional wave power, $J$ & $35 \%$ & $25 \%$ & $20 \%$ \\
Dir. of max dir. resolved power, $\theta_{J \operatorname{lmax}}$ & - & $15^{\circ}$ & $10^{\circ}$ \\
Spectral width, $\varepsilon_{0}$ & - & $25 \%$ & $15 \%$ \\
Directionality coefficient, $d$ & - & $25 \%$ & $15 \%$ \\
\hline
\end{tabular}

$\sigma_{i j}=\sqrt{\frac{1}{N-1} \sum_{k=1}^{N}\left(e_{p_{i j}}-\mu_{i j}\right)^{2}}$

The significance of the systematic and random errors at each cell may be related to their influence on the estimation of the energy resource. Therefore, for each cell $(i, j)$, the product of the proportional frequency of occurrence, $f_{i j}$, and mean incident wave power, $J_{i j}$, gives a strong indication of any error and should constitute the basis for computing the weighting factor, $w_{i j}$ :

$w_{i j}=J_{i j} f_{i j}$

For those cells $(i, j)$, where the minimum number of validation data points is not reached (Table 3 ), $f_{i j}$, must be set to zero. Furthermore, if a specific WEC technology is being considered the weighting factor, $w_{i j}$, may be redefined taking into consideration the capture length, $L_{i j}$, associated with each cell:

$w_{i j}=L_{i j} J_{i j} f_{i j}$

In any case, the weighting matrix shall be normalised such that its sum is equal to one:

$\widehat{w_{i j}}=\frac{w_{i j}}{\sum_{i, j} w_{i j}}$

Therefore, the weighted mean random error, $\sigma\left(e_{p}\right)$, and the weighted systematic error, $b\left(e_{p}\right)$, can be calculated as the sum of the element-wise product of the normalised weighting matrix and the random and systematic error matrices, respectively:

$\sigma\left(e_{p}\right)=\sum_{i, j} \widehat{w_{i j}} \sigma_{i j}$

$b\left(e_{p}\right)=\sum_{i, j} \widehat{w_{i j}} \mu_{i j}$

Table 3 summarises, for each class of resource assessment, the maximum acceptable weighted mean systematic and random errors for every validation parameter.

\section{Case study: Irish West Coast}

As mentioned in Section 1, the Irish West Coast was used as a case study. Due to its large energetic potential, the SEAI (Sustainable Energy Authority of Ireland) intends to develop the Belmullet Wave Energy Test Site, which is located at Annagh Head, west of Belmullet in Co. Mayo, Rep. of Ireland (Fig. 1). The aim of this full scale test site is to assess the performance of WECs for electricity generation and their survivability under open sea conditions. The test site is planned to operate over 20 years offering three separate test locations at different water depths: (i) Near-shore (from $10 \mathrm{~m}$ to $25 \mathrm{~m}$ of water depth), (ii) Mid-water (around $50 \mathrm{~m}$ of water depth) and (iii) Deep-water (around $100 \mathrm{~m}$ of water depth). In addition, the test site will also be equipped with wave and weather buoys, WEC moorings, water pipelines, a submarine electricity cable route, an electrical substation and landing and launching facilities. For these reasons, the Belmullet area was used to compare the performance of the models proposed by the different classes of the IEC-62600101. 

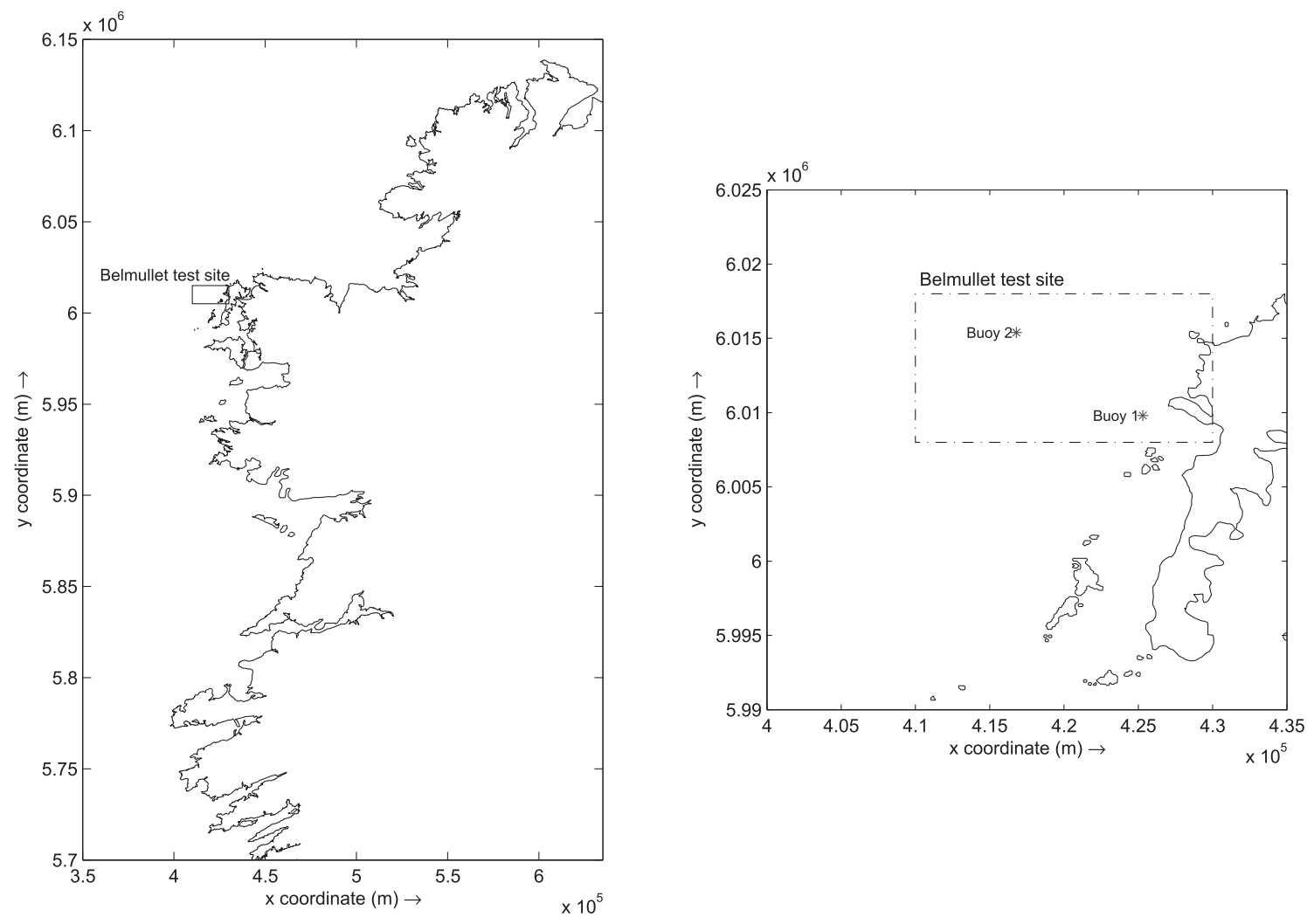

Fig. 1. Ireland's West coast (left) and Belmullet test site (right).

\section{SWAN numerical wave model}

With the aim of determining the wave energy resource in the area of study, the spectral wave model SWAN [39] (Simulating WAves Nearshore) was used. SWAN is an open source thirdgeneration wave model developed by Delft Univeristy of Technology, which has been successfully applied in a large number of studies dealing with wave resource assessment [40-47]. SWAN calculates the development of a sea state based on the wave action density $N(\sigma, \theta)$, since it is conserved in the presence of ambient currents $\vec{U}$, whereas energy density $E(\sigma, \theta)$ is not [39]. The wave action density is defined as the variance density $E$ divided by the relative frequency $(\sigma),(N=E / \sigma)$. The evolution of the action density is governed by the action balance equation, which can be expressed as:

$$
\left.\frac{\partial N}{\partial t}+\nabla_{\vec{x}} \cdot\left[\left(\vec{C}_{g}\right)+\vec{U}\right) N\right]+\frac{\partial c_{\sigma} N}{\partial \sigma}+\frac{\partial c_{\theta} N}{\partial \theta}=\frac{S_{t o t}}{\sigma}
$$

The left-hand side represents the kinematic part of the equation. $\frac{\partial N}{\partial t}$, denotes the evolution of the action density as function of the time. $\left.\nabla_{\vec{x}} \cdot\left[\left(\vec{C}_{g}\right)+\vec{U}\right) N\right]$, represents the propagation of wave energy with the group velocity $\overrightarrow{c_{g}}=\partial \sigma / \partial \vec{k}$ following from the dispersion relation $\sigma^{2}=g|\vec{k}| \tanh (|\vec{k}| d)$ where $\vec{k}$ is the wave number vector and $d$ the water depth. $\frac{\partial c_{\sigma} N}{\partial \sigma}$, stands for the effect of shifting of the radian frequency due to variations in depth and mean currents. Finally, $\frac{\partial c_{\theta} N}{\partial \theta}$, represents the effects of the depth and current induced refraction. The quantities $c_{\sigma}$ and $c_{\theta}$ stand for the propagation velocities in spectral space $(\sigma, \theta)$.

Regarding the right-hand side of Eq. (9), $S_{\text {tot }}$ represents the source/sink term, which takes into account the physical processes of generation, dissipation and nonlinear wave-wave interactions. $S_{\text {tot }}$ can be expressed as follows:

$S_{t o t}=S_{i n}+S_{n l 3}+S_{n l 4}+S_{d s, w}+S_{d s, b}+S_{d s, b r}$

where $S_{i n}$ denotes the wave growth by wind; $S_{n l 3}$ and $S_{n / 4}$ refer to the nonlinear transfer of wave energy through three-wave (triads) and four-wave (quadruplets) interactions, respectively; and finally $S_{d s, w}, S_{d s, b}$ and $S_{d s, b r}$ represent the wave decay due to whitecapping, bottom friction and depth-induced wave breaking, respectively $[39,48,49]$.

Finally, SWAN computes the components of wave power per meter of wave front, $J\left(\mathrm{Wm}^{-1}\right)$ from the full wave spectrum, according to the following expressions:

$J_{x}=\rho g \int_{0}^{2 \pi} \int_{0}^{\infty} c_{g}(\sigma, \mathrm{d}) \mathrm{E}(\sigma, \theta) \cos (\theta) \mathrm{d} \sigma \mathrm{d} \theta$

$J_{y}=\rho g \int_{0}^{2 \pi} \int_{0}^{\infty} c_{g}(\sigma, \mathrm{d}) \mathrm{E}(\sigma, \theta) \sin (\theta) \mathrm{d} \sigma \mathrm{d} \theta$

where $\rho$ is the water density, $g$ is the acceleration due to gravity and $x, y$ are the grid coordinate directions. Therefore, the wave power is calculated as:

$J=\sqrt{\left(J_{x}^{2}+J_{y}^{2}\right)}$ 


\section{Wave model implementation}

Three different spectral wave models, corresponding with the three different classes proposed by the IEC-62600-101, were implemented in the area of study. The model, corresponding with class 1 (MI), spans an area approximately of $90,000 \mathrm{~km}^{2}$, implemented in a structured grid (cartesian) with a resolution of $1000 \times 1000 \mathrm{~m}$ (Fig. 2), which extends from $(x=329,594 \mathrm{~m}$, $y=5,684,380 \mathrm{~m})$ to $(x=602,594 \mathrm{~m}, y=6,153,381 \mathrm{~m})$. With respect to the class 2 model (MII), an area approximately of $18,000 \mathrm{~km}^{2}$ is covered, implemented again in a cartesian grid with a resolution of $500 \times 500 \mathrm{~m}$ (Fig. 3), which extends from $(x=362,000 \mathrm{~m}$, $y=5,910,000 \mathrm{~m})$ to $(x=540,000 \mathrm{~m}, y=6,065,000 \mathrm{~m})$. Finally, for the class 3 model (MIII), the computational domain covers roughly the area occupied by the Belmullet test site (approx. $1480 \mathrm{~km}^{2}$ ), extending from $(x=398,000 \mathrm{~m}, y=5,982,000 \mathrm{~m})$ to $(x=450,000 \mathrm{~m}, y=6,036,000 \mathrm{~m})$. In this case an unstructured mesh was used, which allowed for a much better representation of the coastlines and the areas around the islands than the cartesian grids, and also provided the opportunity to concentrate the mesh resolution in areas of specific interest (i.e. the validation points). The unstructured mesh contains approximately 80,000 cells of

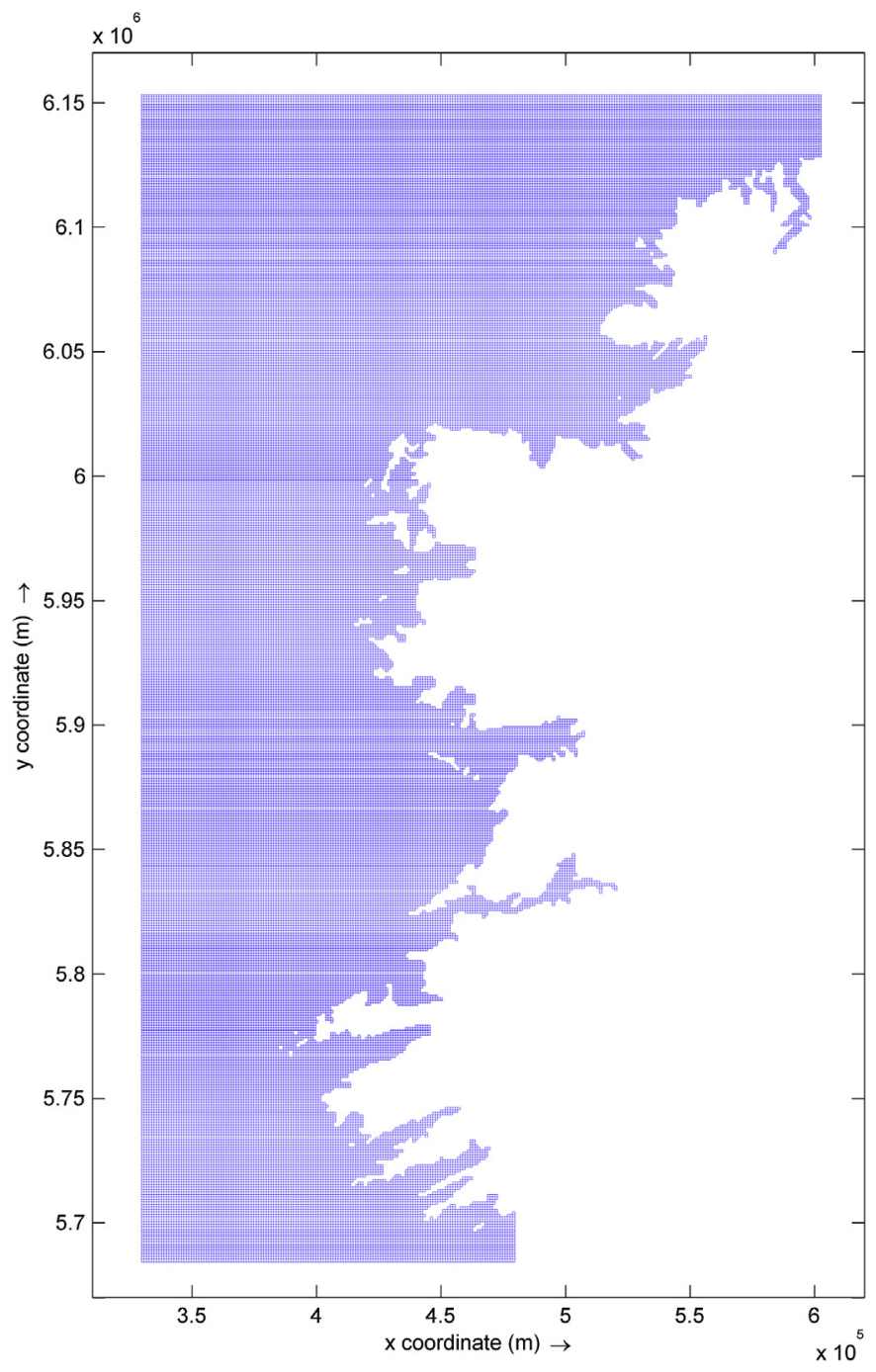

Fig. 2. MI structured computational grid.

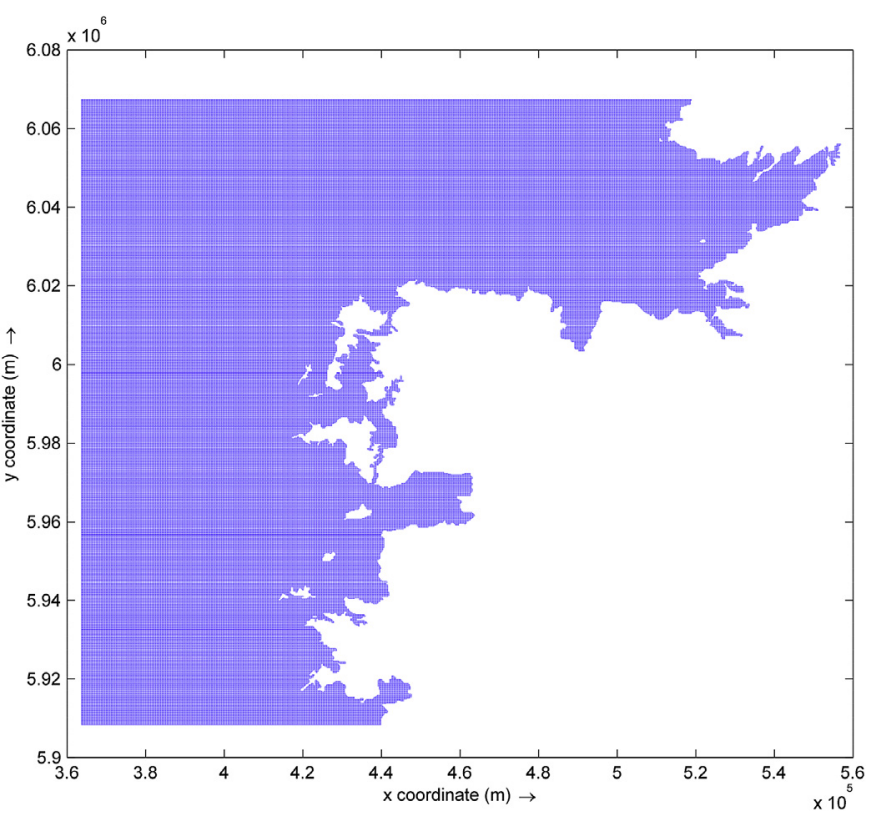

Fig. 3. MII structured computational grid.

triangular shape, with a grid size ranging from $85 \mathrm{~m}$ to $700 \mathrm{~m}$ (Fig. 4).

The bathymetry data for the region of study, which is shown in Fig. 5, was obtained from the British Oceanographic Data Center (BODC) through the General Bathymetric Chart of the Oceans (GEBCO) gridded bathymetric data sets. Then, these data sets were interpolated according to the resolution of the different models (MI, MII and MIII).

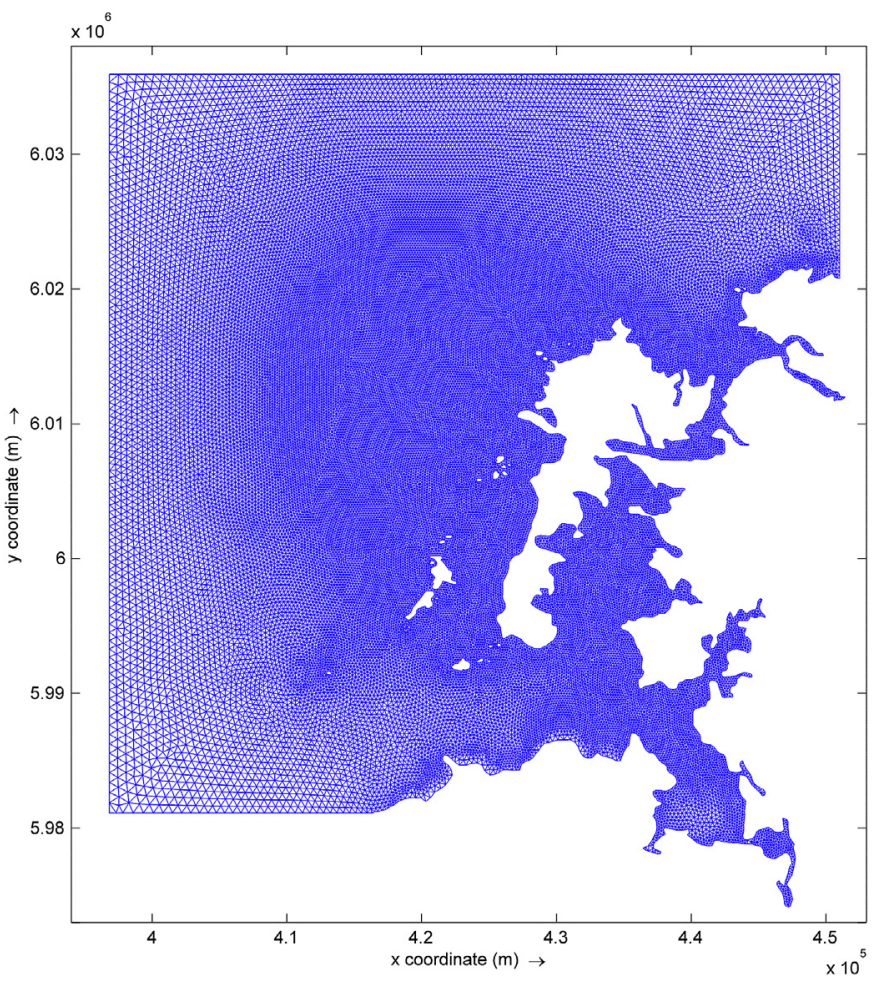

Fig. 4. MIII unstructured computational grid. 


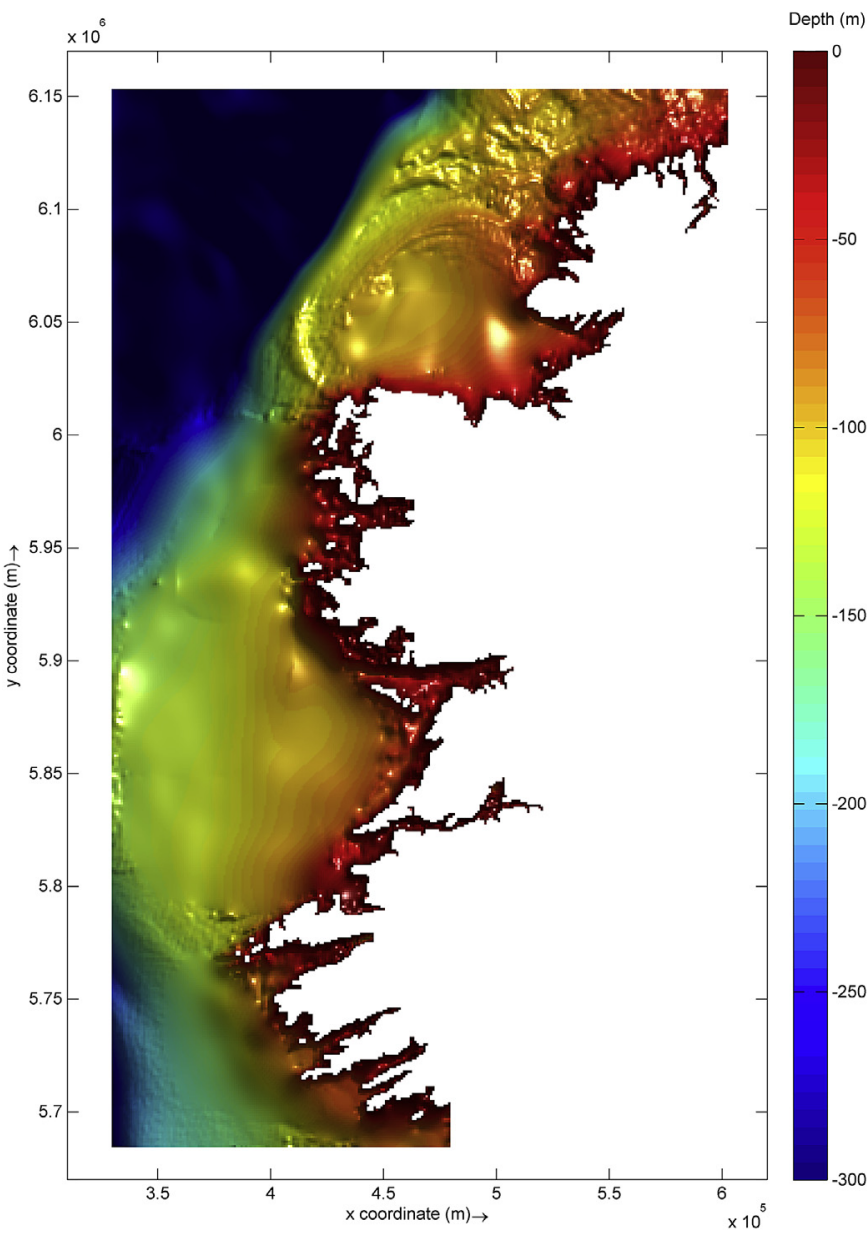

Fig. 5. Bathymetry of the area of study.

The wave boundary conditions used for the model implementation were obtained from the Spanish State Port Authority (Puertos del Estado) through the SIMAR-44 data sets. The SIMAR44 data sets consist of a hindcast obtained through numerical modelling by coupling both a high-resolution atmospheric model (REMO) and a wave model (WAM). The REMO model, which was forced with global reanalysis data from the National Center for Environmental Prediction (NCEP), was used to produce highresolution atmospheric data sets, which were used to force the third generation spectral wave model WAM. The WAM model, like SWAN, solves the action balance equation (Eq. (9)). The model was implemented on a computational grid, which covers all the North Atlantic with a resolution of $30^{\prime}$ (lat) $\times 30^{\prime}$ (lon) without assuming any particular spectral shape and producing results with a frequency of $1 \mathrm{~h}$.
Table 5

Model validation results (\% values), IEC-62600-101 procedure.

\begin{tabular}{lrrr}
\hline & MI & MII & MIII \\
\hline Buoy 1 & & & \\
\hline Coverage & 94.44 & 91.55 & 93.42 \\
$b\left(H_{m 0}\right)$ & 10.90 & 5.66 & 5.54 \\
$b\left(T_{e}\right)$ & 3.71 & 3.62 & 3.43 \\
$b(J)$ & 21.10 & 21.00 & 20.57 \\
$\sigma\left(H_{m 0}\right)$ & 6.55 & 3.72 & 3.77 \\
$\sigma\left(T_{e}\right)$ & 2.57 & 2.51 & 2.50 \\
$\sigma(J)$ & 11.78 & 10.40 & 10.38 \\
\hline Buoy 2 & & & \\
\hline Coverage & & 93.89 & 94.09 \\
$b\left(H_{m 0}\right)$ & 94.47 & 4.78 & 4.64 \\
$b\left(T_{e}\right)$ & 9.38 & 3.98 & 3.56 \\
$b(J)$ & 4.41 & 19.85 & 18.24 \\
$\sigma\left(H_{m 0}\right)$ & 19.95 & 3.52 & 3.15 \\
$\sigma\left(T_{e}\right)$ & 5.30 & 2.50 & 2.47 \\
$\sigma(J)$ & 2.62 & 9.42 & 8.98 \\
\hline
\end{tabular}

Therefore, for the present study, wave data covering a period of ten years from 01/01/2005 to 31/12/2014 with a time interval of $1 \mathrm{~h}$, were extracted from the SIMAR-44 data sets in order to produce the wave boundary conditions for the models MI and MII. As mentioned in Section 2, the characteristics of the wave boundary conditions depend on the class considered. Accordingly, for the class 1 model (MI), the parametrised sea state approach was used, with the sea state conditions limited to the significant wave height, $H_{m 0}(\mathrm{~m})$, the energy period, $T_{E}(\mathrm{~s})$, and the mean wave direction, $\theta_{m}$, (i.e. the direction associated with the principal component of the wave spectrum). Furthermore, for the model MI, an assumption of a spectral shape is required to carry out the propagation of the sea states. In this case, and based on previous wave resource assessments [33], the JONSWAP wave spectrum was used [50]. For model MII (class 2), 2D (directional) wave spectrum data were used with a spatial resolution of $30^{\prime}$. Finally, for model MIII, again space varying 2D (directional) wave spectrum data were used, but in this case they were generated from model MII, which allowed for a much higher spatial resolution $(500 \mathrm{~m})$ alongside the open boundaries.

With respect to the physics of the models only the source term processes (Eq. (10)) that are relevant in shallow waters such as triads $S_{n l 3}$, depth-induced wave breaking $S_{d s, b}$, and bottom friction $S_{d s, b r}$, were included; whereas quadruplets $S_{n l 4}$, whitecapping $S_{d s, w}$ and wave growth induced by wind $S_{i n}$ were turned off. The main characteristics of the various models are summarised in Table 4.

\section{Results}

\subsection{Model validation}

In order to ensure that the models accurately predict the wave conditions in the area of study, they were validated over a period of

Table 4

Characteristics of the various models implemented.

\begin{tabular}{|c|c|c|c|}
\hline & MI & MII & MIII \\
\hline Class & Class 1 & Class 2 & Class 3 \\
\hline Grid & Structured. Cartesian & Structured. Cartesian & Unstructured. Triangular shape \\
\hline Grid resolution & $1000 \times 1000 \mathrm{~m}$ & $500 \times 500 \mathrm{~m}$ & $85-700 \mathrm{~m}$ \\
\hline Boundary conditions & Parametric. Spatially-varying & 2D Spectral. Spatially-varying & 2D Spectral. Spatially-varying \\
\hline Time resolution & $1 \mathrm{~h}$ & $1 \mathrm{~h}$ & $1 \mathrm{~h}$ \\
\hline \multirow[t]{3}{*}{ Physics } & Triads & Triads & Triads \\
\hline & Wave breaking & Wave breaking & Wave breaking \\
\hline & Bottom friction & Bottom friction & Bottom friction \\
\hline
\end{tabular}



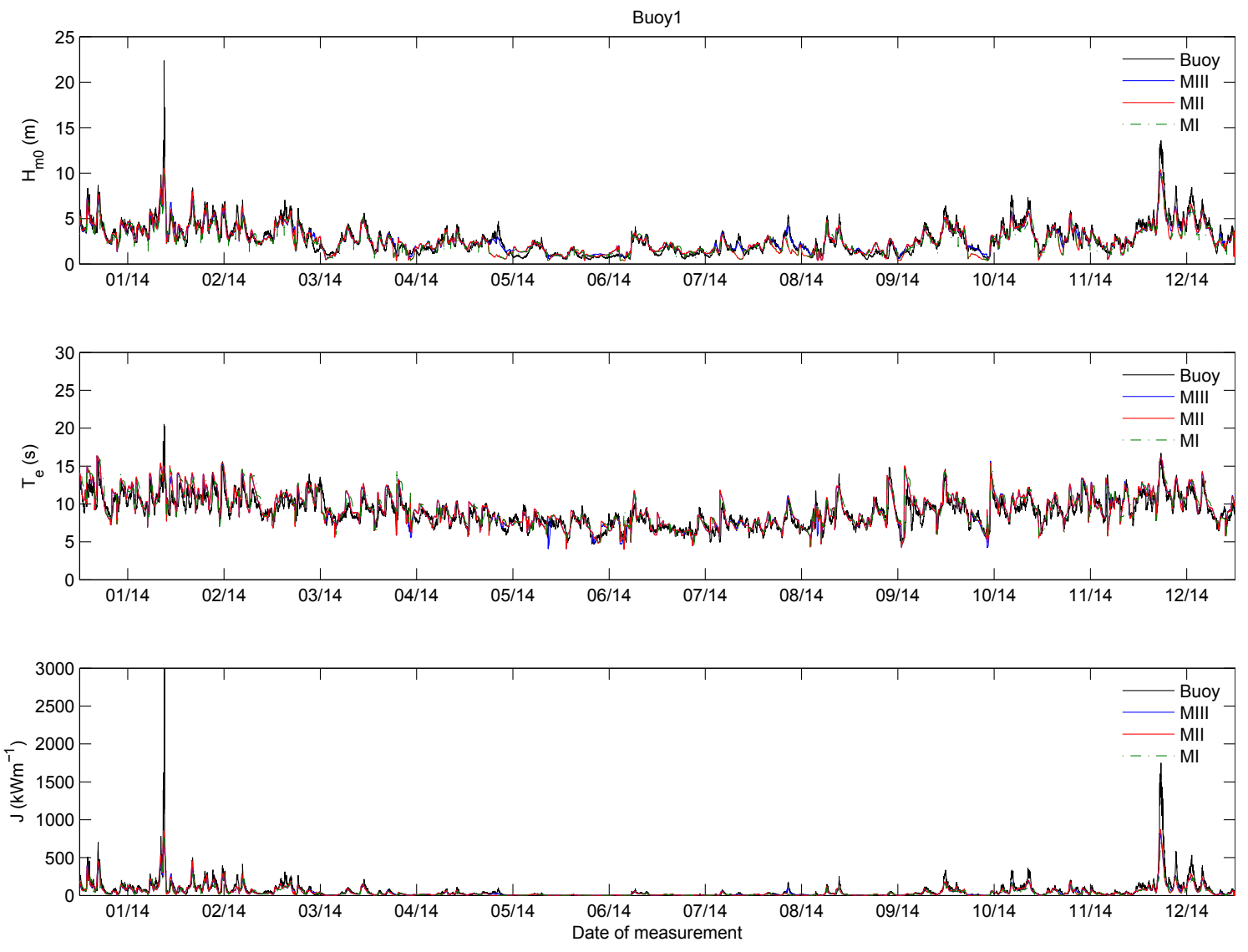

Fig. 6. Buoy 1: Time series of observed and computed wave data, $H_{m 0}, T_{e}, J$.
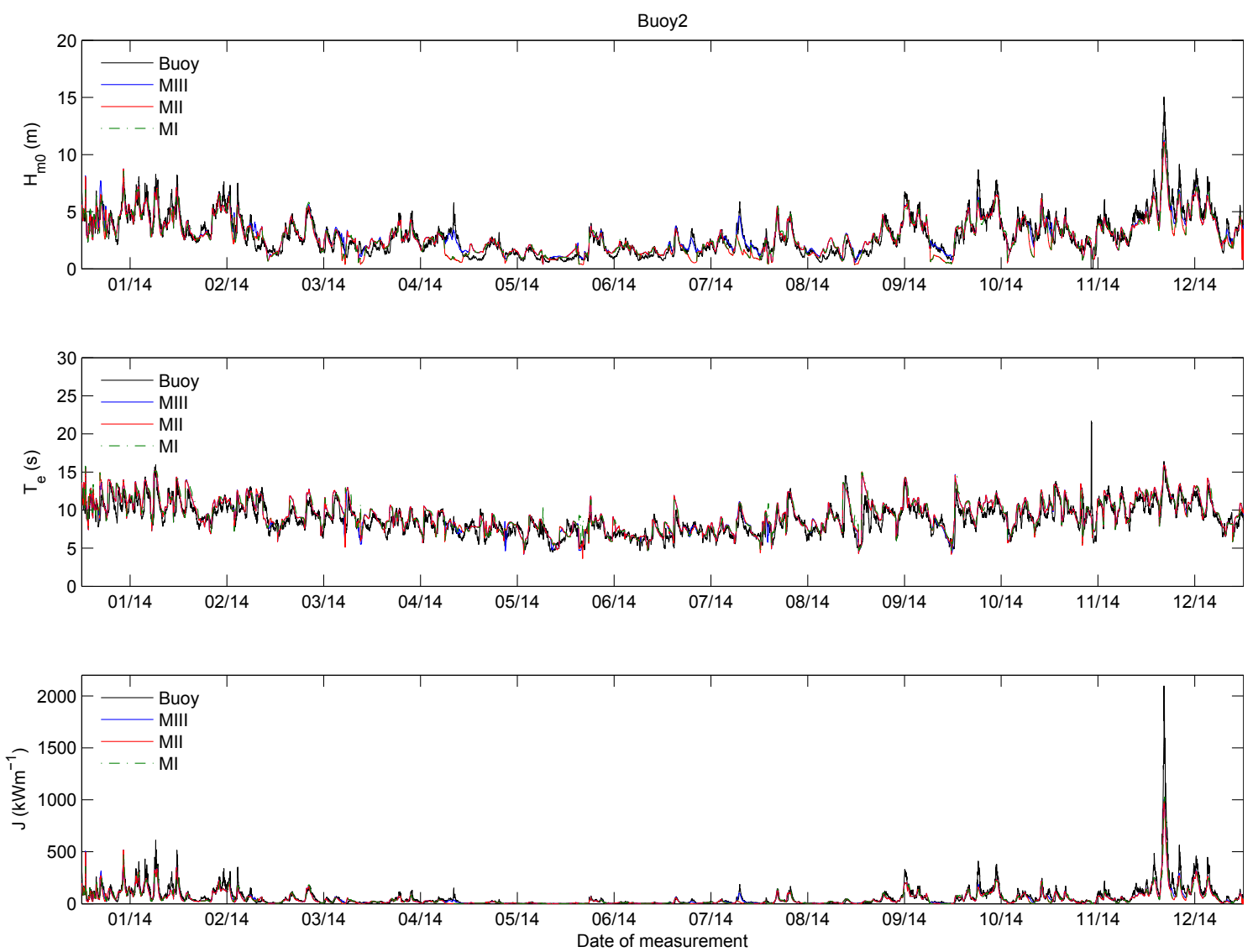

Fig. 7. Buoy 2: Time series of observed and computed wave data, $H_{m 0}, T_{e}, J$. 
Table 6

Summary of main modelling results. Traditional procedure.

\begin{tabular}{lllll}
\hline & & MI & MII & MIII \\
\hline Buoy 1 & & & & \\
\hline$H_{m 0}$ & $R$ & 0.91 & 0.91 & 0.94 \\
& $R M S E(\mathrm{~m})$ & 0.73 & 0.73 & 0.72 \\
& $S I$ & 0.27 & 0.27 & 0.26 \\
$T_{e}$ & $R$ & 0.85 & 0.85 & 0.86 \\
& $R M S E(\mathrm{~s})$ & 1.23 & 1.20 & 1.17 \\
& $S I$ & 0.14 & 0.13 & 0.13 \\
$J$ & $R$ & 0.84 & 0.85 & 0.86 \\
& $R M S E\left(\mathrm{kWm}^{-1}\right)$ & 78.89 & 84.73 & 81.03 \\
& $S I$ & 1.26 & 1.36 & 1.29 \\
\hline Buoy 2 & & & & \\
\hline$H_{m 0}$ & $R$ & 0.90 & 0.91 & 0.94 \\
& $R M S E\left(\mathrm{~m}^{2}\right)$ & 0.78 & 0.73 & 0.68 \\
$T_{e}$ & $S I$ & 0.26 & 0.24 & 0.23 \\
& $R$ & 0.85 & 0.85 & 0.86 \\
& $R M S E(\mathrm{~s})$ & 1.24 & 1.23 & 1.18 \\
$J$ & $S I$ & 0.14 & 0.14 & 0.13 \\
& $R$ & 0.93 & 0.94 & 0.94 \\
& $R M S E\left(\mathrm{kWm}^{-1}\right)$ & 48.13 & 44.44 & 45.32 \\
& $S I$ & 0.78 & 0.72 & 0.74 \\
\hline
\end{tabular}

a year (from 1st January 2014 to 31st December 2014) against hourly wave data, which was obtained from two buoys operated by the Irish Marine Institute in the Belmullet test site (Fig. 1). The validation was carried out following the procedure explained in Section 2, although only the parameters $H_{m 0}, T_{e}$ and $J$ were considered. The results, expressed in percentages, are shown in Table 5.

Overall, an excellent agreement between the calculated and recommended values for the different classes was found. As expected, the results of the validation improved with the degree of refinement of the models, with MIII achieving the best results. However, for models MII and MIII, the mean systematic errors for $b\left(H_{m 0}\right)$ and $b(J)$ present deviations from the recommended values, especially in the case of the wave power $(J)$. It is important to note that the values proposed by the IEC-62600-101 are still provisional and may be revisited based on the feedback of industrial projects or studies like the present one [51].

In addition, the model was also validated following the traditional approach, comparing the time series of computed and measured wave data. Following [34], the Correlation Coefficient, $R$, Root Mean Square Error, RMSE, and Scatter Index, SI, were the statistical parameters used to assess the accuracy of the model. Figs. 6 and 7 show the time series of $H_{m 0}, T_{e}$ and $J$ for the two validation points, with the corresponding statistical analysis summarised in Table 6 . The results obtained indicate again the ability of the models to accurately predict the wave conditions in the area of study (MIII shows again the best agreement), with values of the scatter index SI (RMSE normalised by the mean of the observations) around 0.25 for $H_{m 0}, 0.13$ for $T_{e}$ and 1.30 (Buoy 1) and 0.75 (Buoy 2) for $J$, which confirm the good agreement observed in Figs. 6 and 7.

\subsection{Annual wave resource characterisation}

Following validation, the models were used to estimate the wave resource in the area of study. For this purpose, and following the recommendations of the IEC-62600-101, the model MI (Class I) was run for a period of ten years (from 01/01/2005 to 31/12/2014) with the aim of obtaining a first estimation of the areas with the largest wave energy resource over Ireland's West Coast. The mean annual spatial distribution of wave power (Fig. 8), averaged over the 10 year simulation period, shows that the region presents a

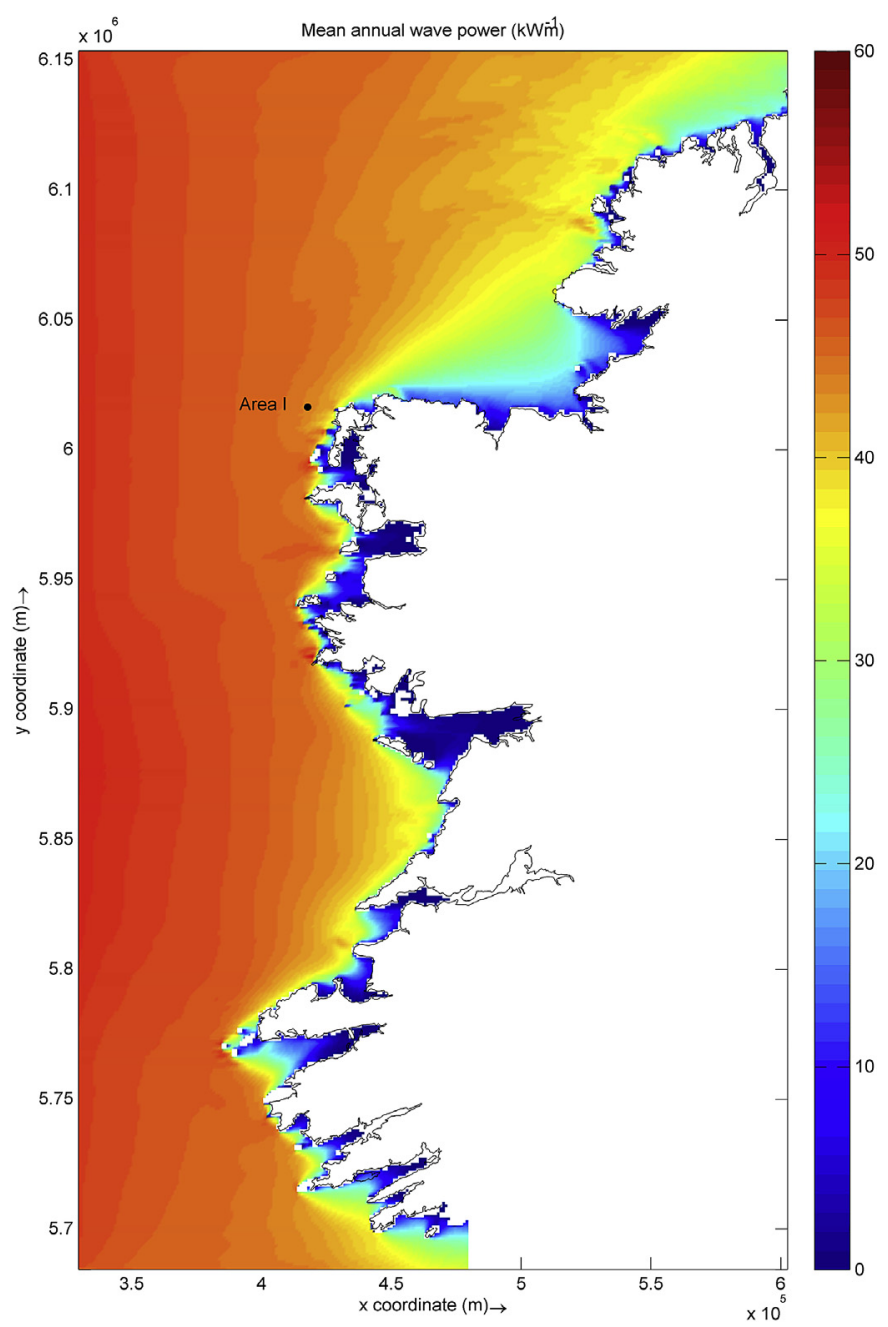

Fig. 8. Mean annual wave power 2005-2014.

remarkable wave energy resource, which is homogeneously distributed with values up to $50 \mathrm{kWm}^{-1}$.

Therefore, Area I in Fig. $8(x=416,790 \mathrm{~m}, y=6,015,400 \mathrm{~m})$, which corresponds with the Belmullet's deep water test site, was selected to assess the wave resource in detail and to compare the performance of the three different models (MI, MII and MIII). For this purpose, the wave conditions for Area I were computed for a period of ten years (from 01/01/2005 to 31/12/2014) with a time interval of $1 \mathrm{~h}$, which translates into 87,648 sea states analysed. Then, following the recommendations of IEC-62600-101, the annual scatter table showing the annual number of hours of each sea state, parametrised in terms of $H_{m 0}$ and $T_{e}$, was constructed. The dimensions of each bin of the scatter table were set to $0.5 \mathrm{~m}$ and $0.5 \mathrm{~s}$ of $H_{m 0}$ and $T_{e}$, respectively, with their upper and lower bounds ensuring that a minimum of $99.9 \%$ sea states were included.

Fig. 9 shows the scatter tables for Area I obtained from the three models (MI, MII and MIII). Overall, it can be observed that the total energy predicted for the models is similar, with some sea states exceeding $7 \mathrm{MWh}^{-1}$; however, MI seems to underestimate the global wave resource in comparison with MII and MIII. With respect to the distribution of the wave resource among the energy bins, considerable differences were found for the different models. For instance, in the case of MIII and MII, the maximum energy is homogeneously concentrated in the range of $3-5 \mathrm{~m}$ of $H_{m 0}$ and 11-12 s of $T_{e}$, whereas in MI the concentration is in the region of 

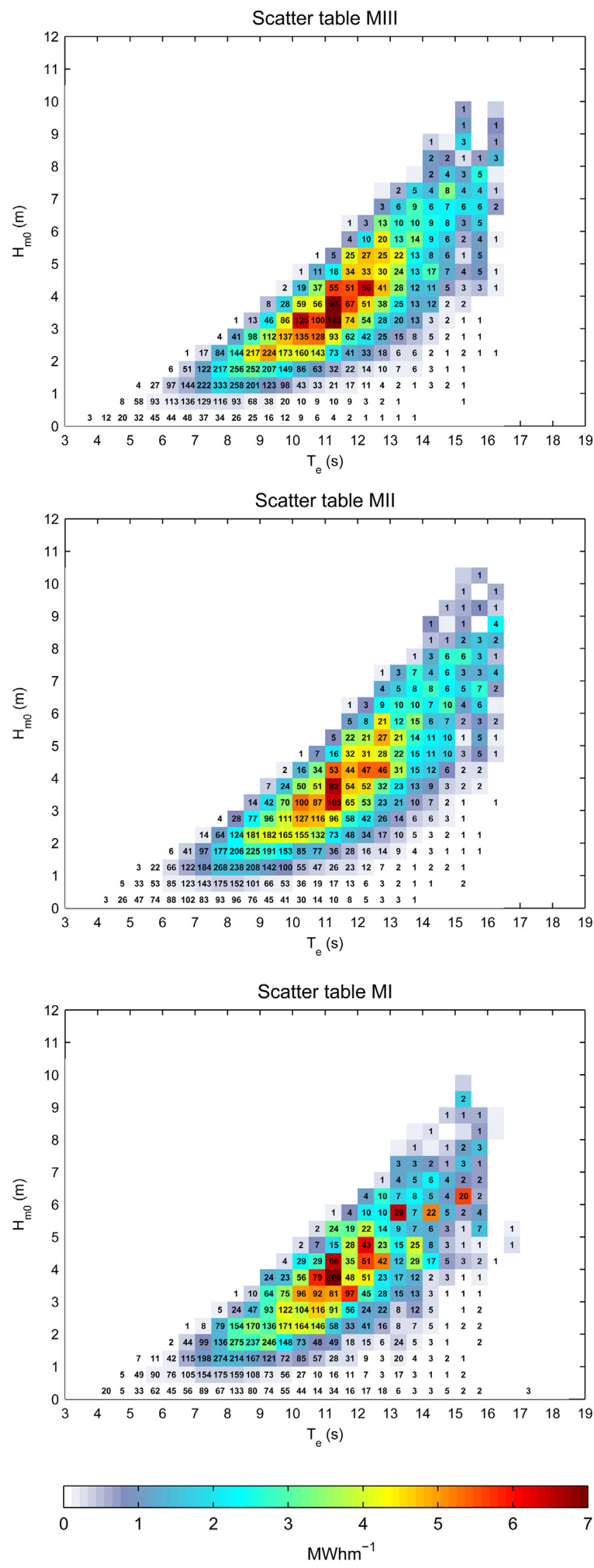

Fig. 9. Scatter tables models MI, MII and MIII. Colour map Energy $\left(\mathrm{MWhm}^{-1}\right)$; Numbers (Num. annual hours energy bin).
4-6 $\mathrm{m}$ of $H_{m 0}$ and 11-13 s of $T_{e}$, with also the presence of some very energetic sea states in the range of $6 \mathrm{~m}$ of $\mathrm{H}_{m 0}$ and $13-15 \mathrm{~s}$ of $T_{e}$. The latter is supported by the results observed in the validation section (Figs. 6 and 7), where MI seems to slightly overestimate the amplitude of the variations of $T_{e}$.

In order to compare the performance of the different model classes, the absolute error for both the mean annual hours and energy of each bin was calculated. For this purpose, MIII was chosen as a reference, since it shows the best agreement with the measured data (Section 6.1). The results obtained are plotted in Fig. 10. It can be observed that the differences between MI and MIII are quite significant, especially in the region of 5-6 $\mathrm{m}$ of $H_{m 0}$ and 12-16 $\mathrm{s}$ of $T_{e}$, where the differences in the estimated energy are close to 55\%. On the other hand, the differences between MII and MIII are considerably less, with only significant differences (up to $25 \%$ ) concentrated in the energy bins of 7-8 $\mathrm{m}$ of $H_{m 0}$ and $14-15 \mathrm{~s}$ of $T_{e}$, which do not present an important number of annual hours. Finally, these results seem to validate the methodology proposed by the IEC-62600-101, highlighting the differences for each class regarding the wave resource characterisation and its distribution among the different energy bins, which can play an important role at the time of designing a wave farm.

\subsection{Intra-annual wave resource characterisation}

Despite the fact that the IEC-62600-101 does not clearly set the need to assess the intra-annual variability of the wave resource, some previous works [32,35,34] have highlighted its importance when estimating the most suitable WEC technologies and their power performances for a particular wave energy site. For all these reasons, the seasonal variations of the wave resource were studied for Area I. Fig. 11 shows the mean available energy for each month of the year computed from the models MI, MII and MIII. As expected [35], large differences throughout the year were found with approximately $72 \%$ of the resource concentrated in the winter period (i.e. from October to March), in which January stands out with values around $60 \mathrm{MWhm}^{-1}$. On the other hand, the summer period (i.e. from April to September) appears to be more stable especially during the months of June, July and August, with values up to $10 \mathrm{MWhm}^{-1}$. Finally, comparing the performance of the different models, MI underestimates the monthly resource, especially during the winter period, with differences up to $12 \%$, whereas MII and MIII offer more similar results, although MII seems to slightly underestimate the wave resource, in comparison with MIII.

The distribution of the wave resource among the energy bins was also studied for the most representative months of the winter and summer periods (i.e. January, April, July and October). Fig. 12 shows the monthly scatter tables computed from the different models MI, MII and MIII. Overall, during the winter months (January and October) the bulk of the wave energy is concentrated in the range of 4-5 $\mathrm{m}$ of $H_{m 0}$ and 11-13 $\mathrm{s}$ of $T_{e}$ while, in the summer months, the contribution to the global resource is significant lower with the energy shifted to lower wave heights and periods (3-4 m of $H_{m 0}$ and 9-10 s of $T_{e}$ ). As shown in Section 6.2, the performance of the different model classes was investigated by computing the absolute error for both the mean monthly hours and energy of each bin, taking MIII as a reference. The results obtained are shown in Fig. 13. Overall, it can be observed that the differences between MII and MIII are almost negligible, with only January offering some relevant differences. On the other hand, the comparison between MI and MIII offers important differences in all cases, specially in January with differences close to $2 \mathrm{MWhm}^{-1}$ in some sea states. All these facts seem to validate the importance of assessing the intraannual variability of the wave resource and also to highlight the relevant differences shown by the different model classes regarding 
Abs. Error Scatter table MI-MIII

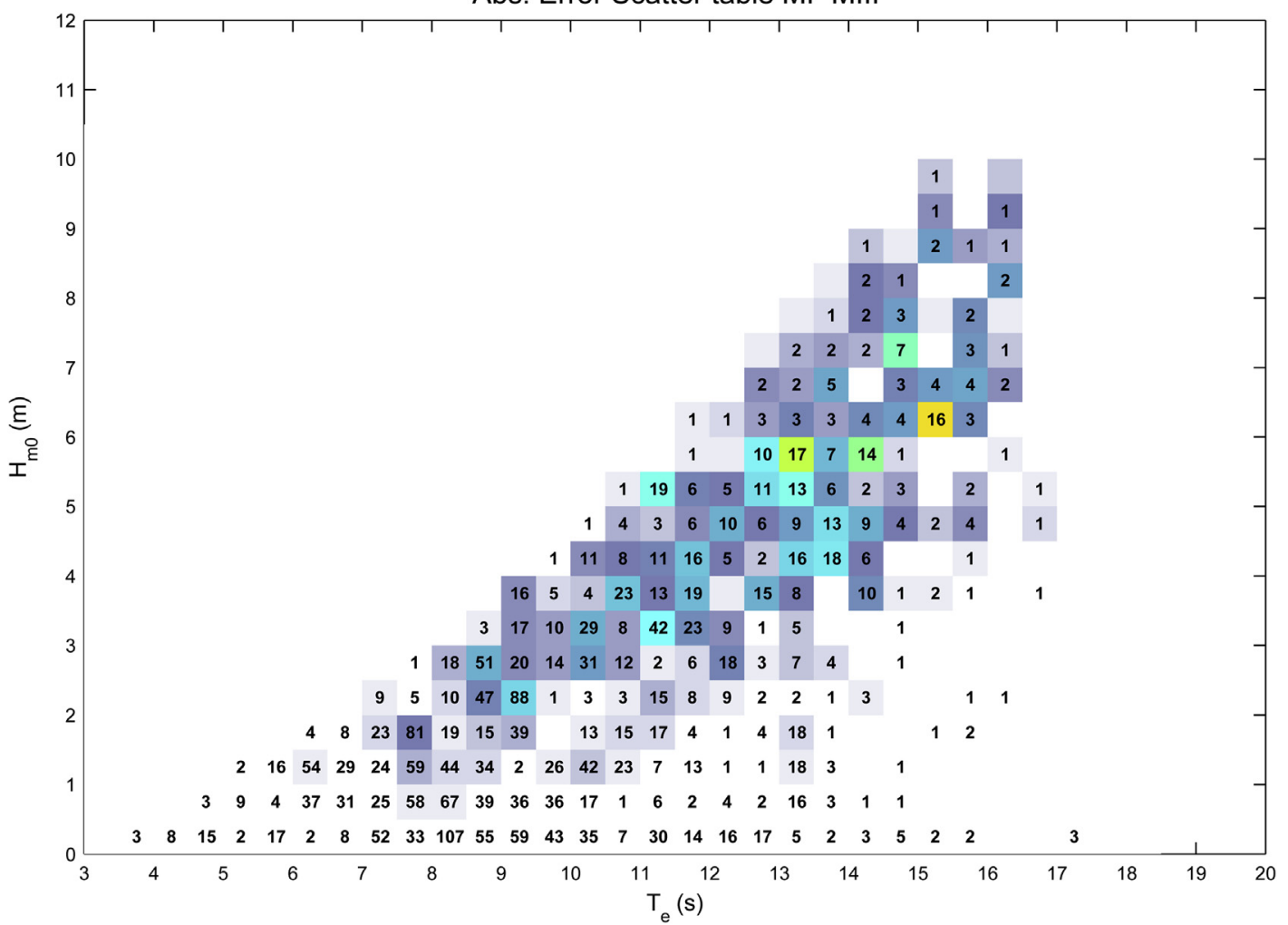

Abs. Error Scatter table MII-MIII

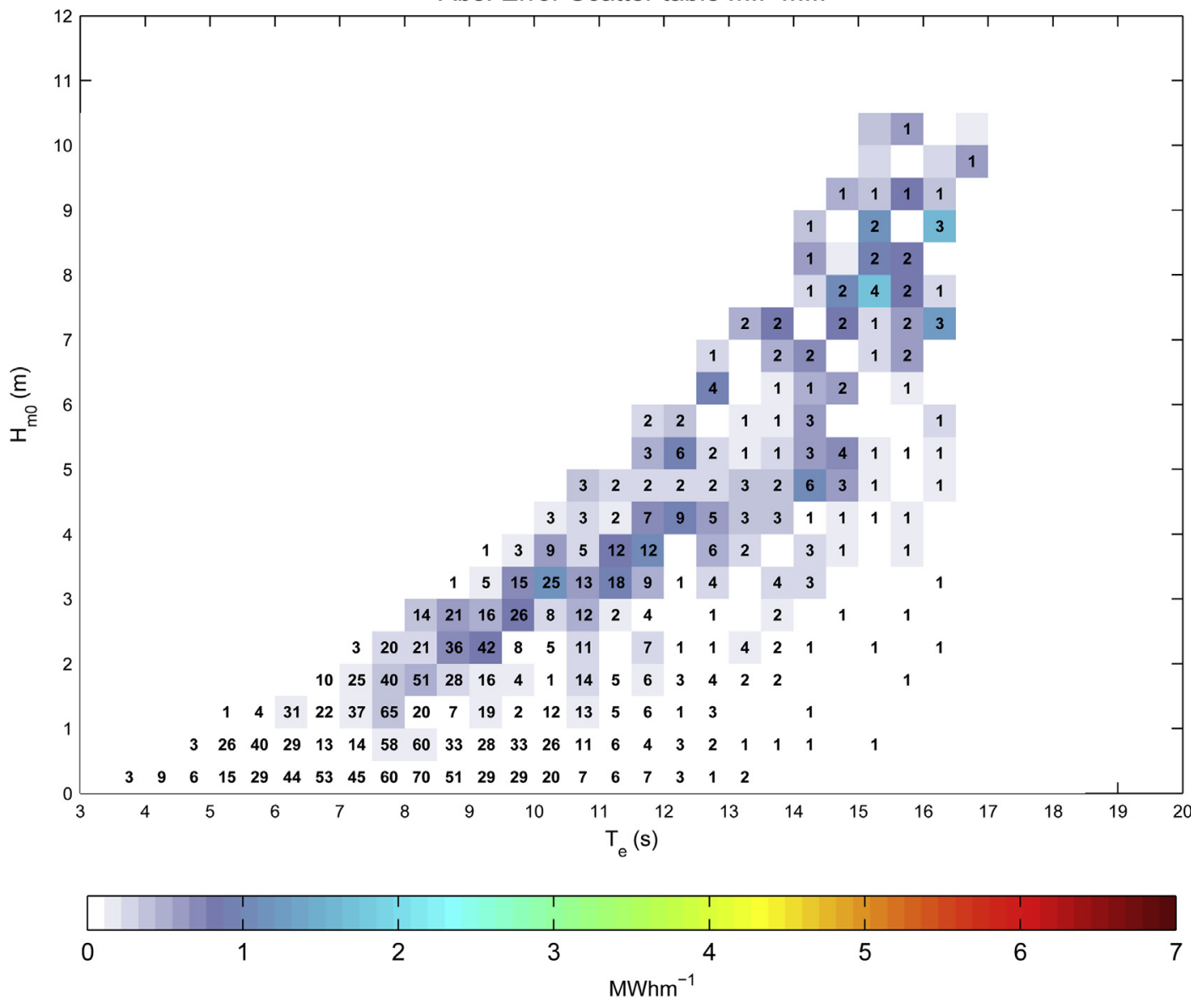

Fig. 10. Absolute error between MI, MII with MIII. Colour map Energy (MWhm ${ }^{-1}$ ); Numbers (Dif. num. annual hours energy bin). 


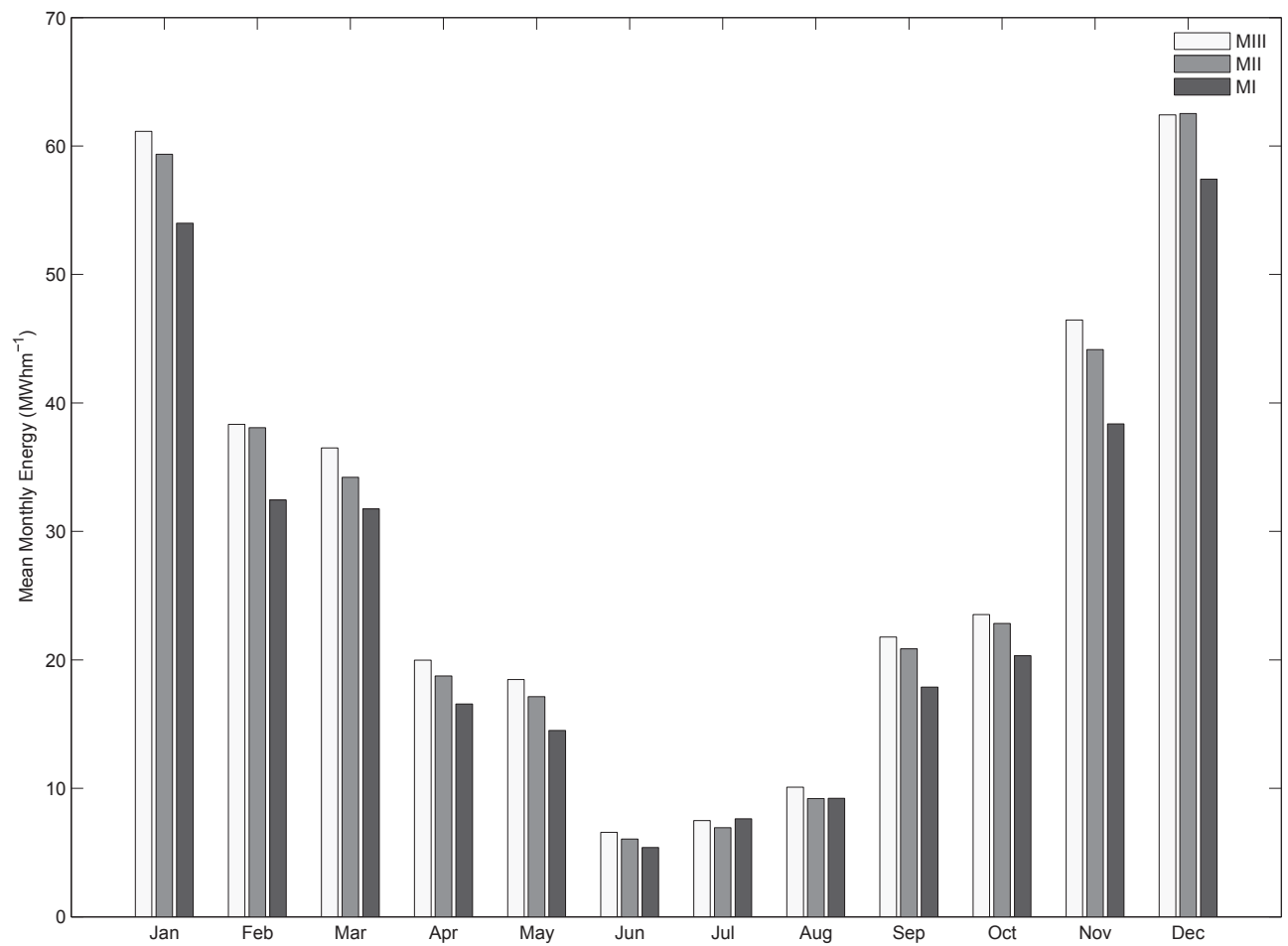

Fig. 11. Mean monthly wave power computed from models MI, MII and MIII.
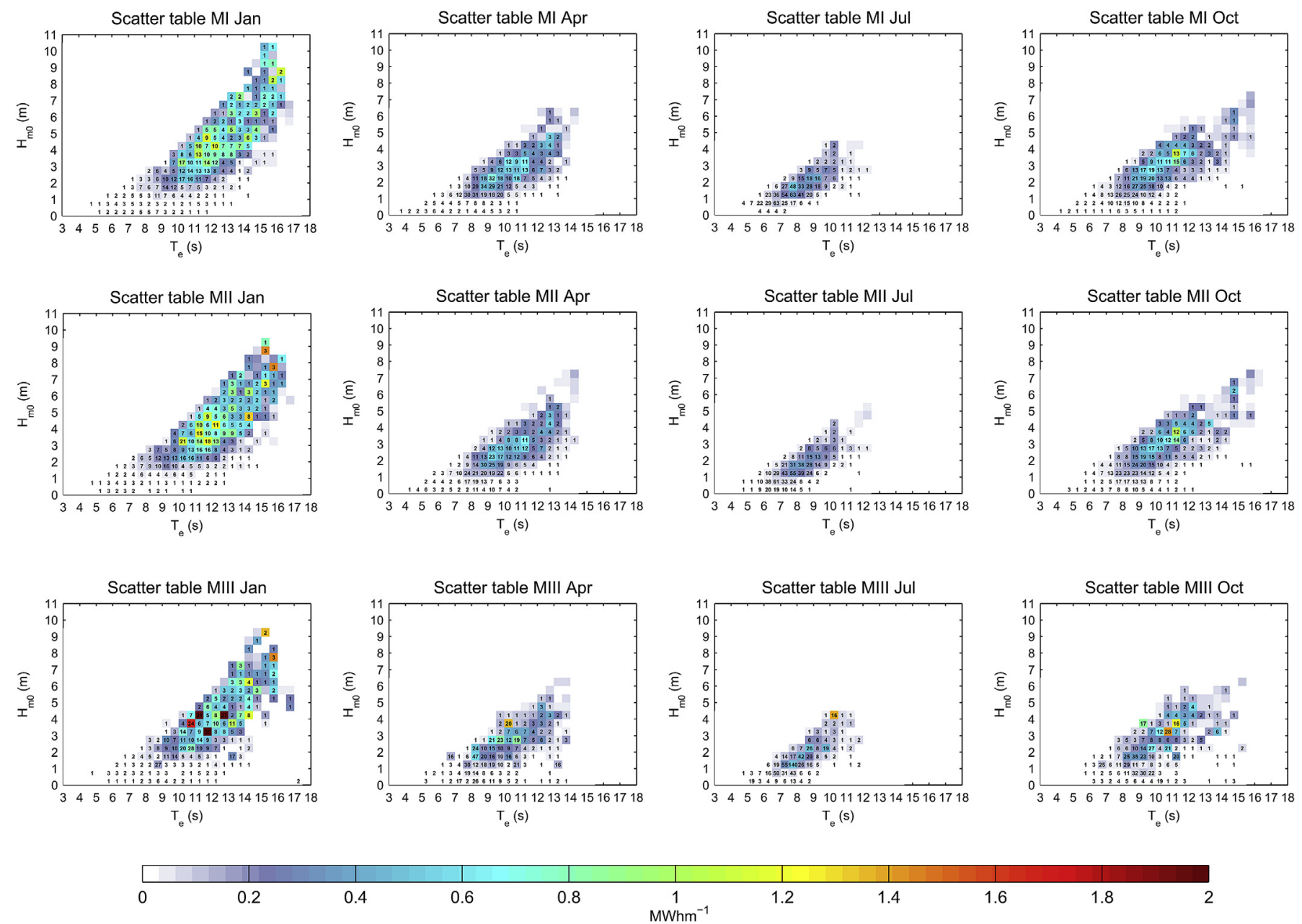

Fig. 12. Monthly scatter tables models MI, MII and MIII. Colour map Energy (MWhm ${ }^{-1}$ ); Numbers (Num. annual hours energy bin). 

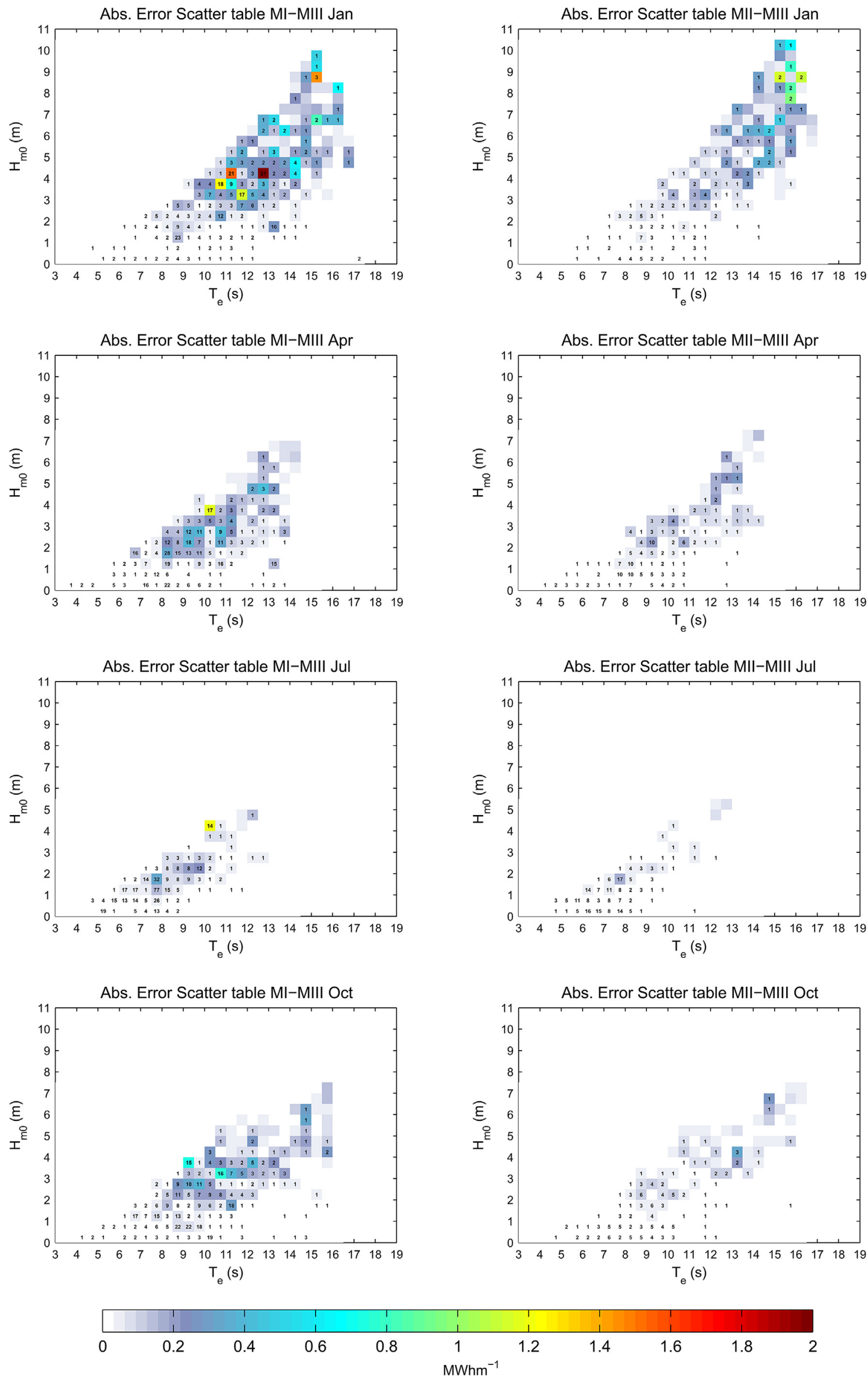

Fig. 13. Monthly absolute error between MI, MII with MIII. Colour map Energy (MWhm ${ }^{-1}$ ); Numbers (Dif. num. annual hours energy bin). 
Table 7

Computational times of models MI, MII and MIII.

\begin{tabular}{llll}
\hline & MI & MII & MIII \\
\hline CPU hours & 172.3 & 192.4 & 294.2 \\
\hline
\end{tabular}

the level of uncertainty in the characterisation of the seasonal wave resource.

\subsection{Computational performance of the models}

The models were also compared from the computational standpoint. The computational tasks were carried out in a HPC facility, the ICHEC (Irish Centre for High-End Computing) using $24 \times 2.4 \mathrm{GHz}$ Intel Xeon E5-2695 cores. Table 7 summarises the CPU hours required for each model. It can be observed that the computational effort required by MIII (class3 model) is significantly higher, which is mainly due to its higher mesh resolution. With respect to MII and MI, classes 2 and 1, respectively; the computational times are quite similar, since the higher resolution of MII $(500 \times 500 \mathrm{~m}$ vs $1000 \times 1000 \mathrm{~m})$ is offset by the smaller area covered by the computational domain of MII $\left(18,000 \mathrm{~km}^{2}\right.$ vs $90,000 \mathrm{~km}^{2}$ ).

\section{Discussion}

This section aims to offer some feedback to the IEC-62600-101, with respect to the main aspects tackled in this investigation: the validation procedure, the wave resource characterisation and the model setup process. The validation procedure has proven to be a robust methodology, which covers a wide range of wave parameters to assess the accuracy of the model. However, there are some issues that may be addressed for future editions of the IEC-62600101. First of all, in view of the results, the maximum acceptable values proposed for the weighted mean systematic error, $b\left(e_{p}\right)$, (Table 3) seem to be especially demanding for classes 2 and 3. As can be observed, for models MII and MIII these requirements are not met for $H_{m 0}$ and $J$; however, the traditional validation procedure shows an excellent agreement in both cases (Table 6 and Figs. 6 and 7). Therefore, taking into account that these maximum limits are still provisional (IEC-62600-101 is still a draft version), these limits may be increased for future editions of the IEC-62600-101. Of course, this also needs to be corroborated from the feedback of studies like the present one carried out for other locations [51,52]. Last, but not least, the IEC-62600-101 should set clear limits regarding the size of the bins of the omni-directional scatter table for the validation procedure. For the moment, the IEC-62600-101 has only stated that the bins should not be larger than $0.5 \mathrm{~m}$ and $1.0 \mathrm{~s}$ of $H_{m 0}$ and $T_{e}$, respectively. However, smalls modifications to the size of the bins may significantly impact the coverage of the validation data (i.e the amount of bins that achieve the minimum number of validation data points to represent the cell) and, therefore, the values obtained for the systematic $b\left(e_{p}\right)$ and random errors $\sigma\left(e_{p}\right)$. Therefore, with the purpose of clarifying and homogenising the validation procedure, IEC-62600-101 should specifically define the size of the scatter table bins.

The methodology proposed by the IEC-62600-101 for the wave resource characterisation appears to perform well for the present case study, proving that the increase in the degree of refinement of the different model classes reduces drastically the level of uncertainty in the estimation of the bulk of the wave resource but also in its distribution among the different energy bins, which plays an important role when selecting the most appropriate WEC technology for a wave energy site. Although IEC-62600-101 does not
Table 8

Comparison among different wave resource assessments based on the IEC-62600101.

\begin{tabular}{lccc}
\hline & Vancouver, canada & Ucluelet, canada & Belmullet, Ireland \\
\hline Grid sensitivity & 0 & $*$ & $*$ \\
Boundary sensitivity & $*$ & $*$ & $*$ \\
Seasonal sensitivity & $*$ & $\bigcirc$ & $*$ \\
Validation sensitivity & $\bigcirc$ & 0 & $*$ \\
Num of years & 7 & 8 & 10 \\
\hline
\end{tabular}

* Considered, $\bigcirc$ Not considered.

explicitly require assessment of the intra-annual variability of the wave resource, the results obtained in this work show its importance in terms of both the behaviour of the wave resource (monthly variability and its distribution amongst the energy bins) and the important differences offered by the different model classes at the time to estimate the monthly resource, which appear to be bigger than the annual scale (especially for the class 1 model, MI). For these reasons, the authors of the present work recommend the inclusion of the assessment of the intra-annual variability of the wave resource in the following editions of the IEC-62600-101.

In addition, the results obtained may also offer some interesting insight into the model setup process. First of all, the results for the present study show that the wave boundary conditions (parametric vs spectral boundaries) play a more important role than the mesh resolution, in relation to the accuracy of the model. As can be observed in Figs. 10 and 13, the results offered by the models MII and MIII, which were set up using spectral boundary conditions (directional wave spectrum), are quite similar, despite the fact that the characteristics of the meshes used are completely different, i.e. a mid-resolution cartesian grid vs a high-resolution unstructured grid, respectively. This fact should not be considered of minor importance, especially to find the right balance between the accuracy and the computational effort required by the model, since a high-resolution model, such as MIII, requires higher computational times (Table 7), whereas the level of accuracy provided is only slightly better than MII. Therefore, taking all these facts into consideration, the requirements for the Class 3 model setup regarding the minimum grid resolution may be revisited for future editions of the IEC-62600-101.

Finally, it is important to point out that all these recommendations are based on the results obtained for the present study and, therefore, they should be supported by other works. For this purpose, more studies like the present one may be carried out under different locations and wave climates with the aim of offering to the IEC-62600-101 a more global feedback for future editions. So far, only a few wave resource assessments based on the IEC-62600-101 were found in the literature [53-55]. Table 8, compares the different aspects related to the IEC-62600-101 tackled in those studies and the work presented in this paper.

\section{Conclusions}

In recent years, the interest in harvesting the wave energy resource has translated into a large number of wave resource assessments. Most of these studies offer a rough approximation of the wave resource, since they were carried out based on a limited number of sea states that do not cover all the energy resource over a specific coastal region. In this context, the IEC has developed a methodology (IEC-62600-101) with the aim of standardising the wave resource characterisation. Therefore, the aim of this work is to explore the utility of the IEC-62600-101 by means of a case study, focussing on the validation procedure and the main aspects of the wave resource characterisation. 
Overall, the IEC-62600-101 has proven to be a robust and coherent methodology, which offers a set of recommendations and rules to carry out a precise wave resource characterisation. The validation procedure covers a wide range of parameters, with the aim of properly assessing the accuracy of the model. However, it was found that the minimum requirements needed for the validation of classes 2 and 3 may be excessively demanding and, therefore, could be subject to change for future versions of the IEC62600-101. Regarding the wave resource estimation, it was found that the degree of uncertainty decreases with the level of refinement of the different model classes both for the annual and intraannual resource characterisation. Furthermore, important intraannual variations of the wave resource were found, which highlights the fact that the assessment of the seasonality of the wave resource should be explicitly included in the IEC-62600-101. From the point of view of the modelling setup, the results obtained show that the characteristics of the boundary conditions (parametric vs spectral) have a bigger impact than the grid resolution on the accuracy of the models. In addition, the grid resolution also plays an important role in the computational effort; therefore, the minimum grid resolution required for the class 3 models could be increased. Finally, it is important to point out that these recommendations should be corroborated with the feedback from other works of the same nature as the present one.

In summary, this work explores the main characteristics of the IEC-62600-101, although some of them such as wave-current interaction are outside the scope of this work and will be dealt with as a continuation of this research.

\section{Acknowledgements}

This research is based upon works supported by Science Foundation of Ireland under Grant No. 12/RC/2302 for the Marine and Renewable Ireland (MAREI) centre. During this work V. Ramos was supported by the I2C postdoctoral grant ED481B 2014/059-0 (Plan Galego de Investigacion Innovacion e Crecemento 2011-2015) of the Xunta de Galicia (Spain). The authors are also indebted to the Spanish Port Authority (Puertos del Estado) for the contribution with the wave boundary data, the Irish Marine Center for providing the wave bouy data from the Belmullet test site and the Irish Centre for High-End Computing (ICHEC) for its cooperation in the computational tasks.

\section{References}

[1] Lund H. Renewable energy strategies for sustainable development. Energy 2007;32(6):912-9. http://dx.doi.org/10.1016/j.energy.2006.10.017. third Dubrovnik Conference on Sustainable Development of Energy, Water and Environment Systems.

[2] Lund H, Mathiesen B. Energy system analysis of $100 \%$ renewable energy systems: the case of Denmark in years 2030 and 2050. Energy 2009;34(5): 524-31. http://dx.doi.org/10.1016/j.energy.2008.04.003. 4th Dubrovnik Conference 4th Dubrovnik conference on Sustainable Development of energy, Water \& Environment.

[3] Rourke FO, Boyle F, Reynolds A. Renewable energy resources and technologies applicable to Ireland. Renew Sustain Energy Rev 2009;13(8):1975-84. http:// dx.doi.org/10.1016/j.rser.2009.01.014.

[4] Bahaj AS. Generating electricity from the oceans. Renew Sustain Energy Rev 2011;15(7):3399-416. http://dx.doi.org/10.1016/j.rser.2011.04.032.

[5] Carballo R, Iglesias G, Castro A. Numerical model evaluation of tidal stream energy resources in the Ria de Muros (NW Spain). Renew Energy 2009;34(6): 1517-24. http://dx.doi.org/10.1016/j.renene.2008.10.028.

[6] Ramos V, Carballo R, Alvarez M, Sanchez M, Iglesias G. A port towards energy self-sufficiency using tidal stream power. Energy 2014;71:432-44. http:/| dx.doi.org/10.1016/j.energy.2014.04.098.

[7] Ramos V, Iglesias G. Performance assessment of tidal stream turbines: a parametric approach. Energy Convers Manag 2013;69:49-57. http:/ dx.doi.org/10.1016/j.enconman.2013.01.008.

[8] Veigas M, Carballo R, Iglesias G. Wave and offshore wind energy on an island. Energy Sustain Dev 2014;22:57-65. http://dx.doi.org/10.1016 j.esd.2013.11.004. Wind Power Special Issue.
[9] Veigas M, Iglesias G. Wave and offshore wind potential for the island of Tenerife. Energy Convers Manag 2013;76:738-45. http://dx.doi.org/10.1016/ j.enconman.2013.08.020.

[10] Ashton I, Van-Nieuwkoop-McCall J, Smith H, Johanning L. Spatial variability of waves within a marine energy site using in-situ measurements and a high resolution spectral wave model. Energy 2014;66:699-710. http://dx.doi.org/ 10.1016/j.energy.2013.12.065.

[11] Besio G, Mentaschi L, Mazzino A. Wave energy resource assessment in the Mediterranean Sea on the basis of a 35-year hindcast. Energy 2016;94:50-63. http://dx.doi.org/10.1016/j.energy.2015.10.044.

[12] Iglesias G, Carballo R. Choosing the site for the first wave farm in a region: a case study in the Galician Southwest (Spain). Energy 2011;36(9):5525-31. http://dx.doi.org/10.1016/j.energy.2011.07.022.

[13] Rusu L, Soares CG. Wave energy assessments in the Azores Islands. Renew Energy 2012;45:183-96. http://dx.doi.org/10.1016/j.renene.2012.02.027.

[14] Rusu E, Soares CG. Numerical modelling to estimate the spatial distribution of the wave energy in the Portuguese nearshore. Renew Energy 2009;34(6): 1501-16. http://dx.doi.org/10.1016/j.renene.2008.10.027.

[15] Gonçalves M, Martinho P, Soares CG. Wave energy conditions in the western French coast. Renew Energy 2014;62:155-63. http://dx.doi.org/10.1016/ j.renene.2013.06.028

[16] Gonçalves M, Martinho P, Soares CG. Assessment of wave energy in the Canary Islands. Renew Energy 2014;68:774-84. http://dx.doi.org/10.1016/ j.renene.2014.03.017.

[17] Iglesias G, Lopez M, Carballo R, Castro A, Fraguela J, Frigaard P. Wave energy potential in Galicia (NW Spain). Renew Energy 2009;34(11):2323-33. http:/1 dx.doi.org/10.1016/j.renene.2009.03.030.

[18] Iglesias G, Carballo R. Wave resource in El Hierro: an island towards energy self-sufficiency. Renew Energy 2011;36(2):689-98. http://dx.doi.org/ 10.1016/j.renene.2010.08.021.

[19] Iglesias G, Carballo R. Wave energy and nearshore hot spots: the case of the SE Bay of Biscay. Renew Energy 2010;35(11):2490-500. http://dx.doi.org/ 10.1016/j.renene.2010.03.016.

[20] Alonso R, Solari S, Teixeira L. Wave energy resource assessment in Uruguay.

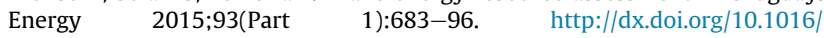
j.energy.2015.08.114.

[21] Rusu L, Onea F. Assessment of the performances of various wave energy converters along the European continental coasts. Energy 2015;82:889-904. http://dx.doi.org/10.1016/j.energy.2015.01.099.

[22] Zhou G, Huang J, Zhang G. Evaluation of the wave energy conditions along the coastal waters of Beibu Gulf, China. Energy 2015;85:449-57. http:// dx.doi.org/10.1016/j.energy.2015.03.094.

[23] Astariz S, Iglesias G. The economics of wave energy: a review. Renew Sustain Energy Rev 2015;45:397-408. http://dx.doi.org/10.1016/j.rser.2015.01.061.

[24] Iglesias G, Carballo R. Wave farm impact: the role of farm-to-coast distance. Renew Energy 2014;69:375-85. http://dx.doi.org/10.1016/ j.renene.2014.03.059.

[25] Carballo R, Iglesias G. Wave farm impact based on realistic wave-WEC interaction. Energy 2013;51:216-29. http://dx.doi.org/10.1016/ j.energy.2012.12.040.

[26] Mackay EB, Bahaj AS, Challenor PG. Uncertainty in wave energy resource assessment. Part 1: historic data. Renew Energy 2010;35(8):1792-808. http:// dx.doi.org/10.1016/j.renene.2009.10.026.

[27] Mackay EB, Bahaj AS, Challenor PG. Uncertainty in wave energy resource assessment. Part 2: variability and predictability. Renew Energy 2010;35(8): 1809-19. http://dx.doi.org/10.1016/j.renene.2009.10.027.

[28] Farrell N, Donoghue CO, Morrissey K. Quantifying the uncertainty of wave energy conversion device cost for policy appraisal: an Irish case study. Energy Policy 2015;78:62-77. http://dx.doi.org/10.1016/j.enpol.2014.11.029.

[29] Lopez M, Veigas M, Iglesias G. On the wave energy resource of Peru. Energy Convers Manag 2015;90:34-40. http://dx.doi.org/10.1016/ j.enconman.2014.11.012.

[30] Veigas M, Lopez M, Iglesias G. Assessing the optimal location for a shoreline wave energy converter. Appl Energy 2014;132:404-11. http://dx.doi.org/ 10.1016/j.apenergy.2014.07.067.

[31] Carballo R, Iglesias G. A methodology to determine the power performance of wave energy converters at a particular coastal location. Energy Convers Manag 2012;61:8-18. http://dx.doi.org/10.1016/j.enconman.2012.03.008.

[32] Carballo R, Sanchez M, Ramos V, Fraguela J, Iglesias G. Intra-annual wave resource characterization for energy exploitation: a new decision-aid tool. Energy Convers Manag 2015;93:1-8. http://dx.doi.org/10.1016/ j.enconman.2014.12.068.

[33] Carballo R, Sanchez M, Ramos V, Fraguela J, Iglesias G. The intra-annual variability in the performance of wave energy converters: a comparative study in N Galicia (Spain). Energy 2015;82:138-46. http://dx.doi.org/10.1016/ j.energy.2015.01.020.

[34] Neill SP, Lewis MJ, Hashemi MR, Slater E, Lawrence J, Spall SA. Inter-annual and inter-seasonal variability of the Orkney wave power resource. Appl Energy 2014;132:339-48. http://dx.doi.org/10.1016/j.apenergy.2014.07.023.

[35] Neill SP, Hashemi MR. Wave power variability over the northwest European shelf seas. Appl Energy 2013;106:31-46. http://dx.doi.org/10.1016/ j.apenergy.2013.01.026.

[36] IEC-ts 62600-101. Marine energy wave, tidal and other water current converters part 101: wave energy resource assessment and characterisation. 2014. 
[37] Tiron R, Gallagher S, Gleeson E, Dias F, McGrath R. The future wave climate of Ireland: from averages to extremes. Procedia \{IUTAM\} 2015;17:40-6. http:/ dx.doi.org/10.1016/j.piutam.2015.06.007 \{IUTAM\} Symposium on the Dynamics of Extreme Events Influenced by Climate Change (2013).

[38] Cahill B, Lewis T. Wave energy resource characterisation of the atlantic marine energy test site. Int J Mar Energy 2013;1:3-15. http://dx.doi.org/10.1016/ j.ijome.2013.05.001.

[39] Delft University of Techonology. SWAN User manual. 1993-2014.

[40] Bento AR, Martinho P, Soares CG. Numerical modelling of the wave energy in Galway Bay. Renewable Energy 2015;78:457-66. http://dx.doi.org/10.1016/ j.renene.2015.01.024.

[41] Silva D, Bento AR, Martinho P, Soares CG. High resolution local wave energy modelling in the Iberian Peninsula. Energy 2015;91:1099-112. http:// dx.doi.org/10.1016/j.energy.2015.08.067.

[42] Soares CG, Bento AR, Gonçalves M, Silva D, Martinho P. Numerical evaluation of the wave energy resource along the Atlantic European coast. Comput Geosci 2014;71:37-49. http://dx.doi.org/10.1016/j.cageo.2014.03.008. marine Renewable Energy.

[43] Iglesias G, Carballo R. Offshore and inshore wave energy assessment: Asturias (N Spain). Energy 2010;35(5):1964-72. http://dx.doi.org/10.1016/ j.energy.2010.01.011.

[44] Iglesias G, Carballo R. Wave energy resource in the Estaca de Bares area (Spain). Renew Energy 2010;35(7):1574-84. http://dx.doi.org/10.1016/ j.renene.2009.10.019. special Section: \{IST\} National Conference 2009.

[45] Iglesias G, Carballo R. Wave energy potential along the Death Coast (Spain). $\begin{array}{lll}\text { Energy } & \text { 2009;34(11):1963-75. http://dx.doi.org/10.1016/ }\end{array}$ j.energy.2009.08.004.

[46] Lewis M, Neill S, Hashemi M, Reza M. Realistic wave conditions and their influence on quantifying the tidal stream energy resource. Appl Energy 2014;136:495-508. http://dx.doi.org/10.1016/j.apenergy.2014.09.061.
[47] Hashemi MR, Neill SP, Robins PE, Davies AG, Lewis MJ. Effect of waves on the tidal energy resource at a planned tidal stream array. Renew Energy 2015;75: 626-39. http://dx.doi.org/10.1016/j.renene.2014.10.029.

[48] Van der Westhuysen AJ [Thesis]. The application of the numerical wind-wave model SWAN to a selected field case on the South African Coast. the University of Stellenbosch, South Africa; 2002.

[49] Holthuijsen LH, Booij N, Ris RC. A third-generation wave model for coastal regions: 1. Model description and validation. J Geophys Res Oceans 1999;104 7649-66.

[50] Isherwood R. Technical note: a revised parameterisation of the JONSWAP spectrum. Appl Ocean Res 1987;9(1):47-50. http://dx.doi.org/10.1016/01411187(87)90030-7.

[51] Cornett A, Baker S, Toupin M, Piche S, Nistor I. Appraisal of IEC standards for wave and tidal energy resource assessment. In: International conference on ocean energy (ICOE); November 4-6, 2014.

[52] Piche S, Cornett A, Baker S, Nistor I. Appraisal of the IEC technical specification for assessment of wave energy resources. In: ASME 2015 34th International conference on ocean, Offshore and Arctic Engineering. American Society of Mechanical Engineers; 2015. V009T09A034-V009T09A034.

[53] Piche S, Cornett A, Baker S, Nistor I. Validation of the IEC technical specification for wave energy resource assessment. In: Proceedings of the 11th European wave and tidal energy conference; 2015.

[54] Cornett A, Toupin M, Nistor I. Appraisal of IEC technical specification for tidal energy resource assessment at Minas Passage, Bay of Fundy, Canada. In: Proceedings of the 11 th European wave and tidal energy conference 2015.

[55] Robertson BR, Hiles CE, Buckham BJ. Characterizing the near shore wave energy resource on the west coast of Vancouver Island, Canada. Renew Energy 2014;71:665-78. http://dx.doi.org/10.1016/j.renene.2014.06.006. 